\title{
How do small firms respond to tax schedule discontinuities? Evidence from South African tax registers
}

\author{
Wian Boonzaaier ${ }^{1} \cdot$ Jarkko Harju ${ }^{2,3} \cdot$ Tuomas Matikka $^{2,3} \cdot J_{\text {Jkka Pirttilä2,3,4,5 }}$
}

Published online: 6 June 2019

(c) UNU-WIDER 2019

\begin{abstract}
We study the responsiveness of small- and medium-sized firms to a small-business corporate income tax schedule using population-wide administrative data from South Africa. We find sizeable bunching of firms at the corporate income thresholds where the corporate tax rate increases, implying active responses to corporate income taxes. The observed bunching is very sharp and reacts immediately to changes in the location of the kink points. These observations suggest that a sizeable part of the response is driven by reporting responses rather than real economic behavior. We find indicative evidence that reporting behavior is linked to underreporting of sales and legal taxplanning activities.
\end{abstract}

Keywords Corporate taxation · Small firms · Emerging economies · Bunching

JEL Classification $\mathrm{H} 21 \cdot \mathrm{H} 25 \cdot \mathrm{H} 32 \cdot \mathrm{O} 12$

$凶 \quad$ Jukka Pirttilä

jukka.pirttila@helsinki.fi

Wian Boonzaaier

wian.boonzaaier@gmail.com

Jarkko Harju

jarkko.harju@vatt.fi

Tuomas Matikka

tuomas.matikka@vatt.fi

1 South African Reserve Bank and National Treasury, Pretoria, South Africa

2 VATT Institute for Economic Research, Helsinki, Finland

3 CESifo, Munich, Germany

4 University of Helsinki, Helsinki, Finland

5 UNU-WIDER, Helsinki, Finland

Springer 


\section{Introduction}

Emerging or transition economies such as South Africa need to secure a sufficient revenue base to finance developmental activities by the state and to fight poverty and inequality. At the same time, these countries need to make sure that the distortions created by the tax system are kept at bay so that the tax burden does not hinder job creation and productivity growth. An essential element in understanding the welfare consequences of the tax system is to have reliable evidence of the behavioral impact of taxes. In developed countries, what is nowadays regarded as credible evidence is studies that use comprehensive administrative taxpayer data to examine the consequences of exogenous changes in tax legislation over time or between similar taxpayers. Such 'New Tax Responsiveness' literature has been summarized by, for example, Saez et al. (2012) and Kleven (2016).

However, the literature providing similar micro-level evidence with credible identification strategies using data from developing countries or emerging economies is scarce, with two studies on Pakistani data being the prime exceptions (see Kleven and Waseem 2013; Best et al. 2015). The need for more evidence is quite pressing, as it is likely that behavioral responses may well differ across countries. For example, lowand middle-income countries typically have lower revenue-raising capacity, and this likely impacts the possibilities for tax avoidance and evasion. The elasticity estimates for reported income from these types of countries can therefore be greater than in developed countries, at least for this reason.

One particular avenue where emerging economies need to make progress is job and value creation in the formal sector. Much of this is bound to arise from small- and medium-sized enterprises. Guidance on how tax policies affect the behavior of such firms is even harder to find, even for developed countries. The body of research on the impact of taxes on small-business behavior, including tax avoidance and potential growth impacts, is still relatively small, although currently expanding.

In this paper, we examine the impact of a small-business corporate income tax schedule (SBC) on small- and medium-sized firms (SME) using population-wide, high-quality administrative data from the South African Revenue Service. This paper is one of the first to provide evidence of the elasticity of corporate income in emerging economies. This is the first time such evidence has been generated using administrative tax data from Africa. ${ }^{1}$

We utilize discontinuous changes in tax incentives created by the graduated, progressive corporate income tax (CIT) schedule for small- and medium-sized firms to identify the causal effect of taxes on firm behavior. Recent literature, starting with Saez (2010) and summarized in Kleven (2016), shows that these kink points create incentives for firms to locate right at them, and this so-called bunching phenomenon can be used to estimate the extent of the distortions caused by the tax system. Intu-

\footnotetext{
1 After writing the first version of the paper (Boonzaaier et al. 2016), we learnt about the still incomplete and unpublished working paper by Lediga et al. (2016), who also use South African data and examine the responses to kink points. While there are similarities with the analyses (they also find significant responses to CIT kink points), the focus of the two papers is different. Lediga et al. (2016) mainly concentrate on the auditing strategies of the revenue authority, whereas our paper looks in detail at the changes in kink points and the anatomy of the response.
} 
itively, the more the firms bunch at these tax rate thresholds, the more elastic the tax base is, and the greater the distortions are.

In addition, we characterize the role of reporting responses (evasion/avoidance) and real economic responses (changes in true output) in explaining observed behavior. Both real and reporting responses have a similar effect on tax revenue, at least in the short run. However, decomposition of the response is of great importance when considering the effectiveness of tax policy, particularly when considering the efficiency of tax revenue collection. For example, in the case of significant real output responses, a reduction in tax revenue due to a reduced tax rate can be more easily justified by the increased real economic activity (and vice versa). ${ }^{2}$ Admittedly, it is difficult to obtain causal evidence of the different mechanisms at play. However, by utilizing detailed administrative data and changes in the location of the CIT kink points, we provide several pieces of descriptive evidence that help us to outline the likely drivers of the observed overall responses.

We find very large responses to discontinuities in the CIT schedule. There is distinctive and sizeable excess bunching at the kink points in the corporate income distribution, and the corresponding local corporate taxable income elasticities with respect to the CIT rate are 0.17 at the upper CIT kink (350,000 Rand or around 26,000 USD) and 0.7 at the lower kink (60,000 Rand). When zooming into the anatomy of the response, our descriptive evidence suggests that changes in reporting behavior are likely to explain a notable share of the overall response. One noteworthy phenomenon we document is that firms react to changes in the location of kink points by a greater change in reported sales than in reported costs. These findings suggest that the original goal of encouraging economic activity and job creation by applying a graduated corporate tax rate schedule is at least partly mitigated by the lack of distinctive real economic responses to tax incentives.

Our paper is closely related to the analysis of progressive corporate income taxation by Devereux et al. (2014), who show that bunching at CIT kinks identifies the elasticity of the corporate income tax base. They find that firms in the UK bunch significantly and sharply at the kink points of a similar CIT rate schedule as in South Africa, and find evidence of income-shifting between corporate and personal tax bases that largely explains the behavioral response. Naturally, the work on taxation and development, surveyed recently by Keen (2012) and Besley and Persson (2013), is also closely related. ${ }^{3}$ In addition to the studies on Pakistani data by Kleven and Waseem (2013) and Best et al. (2015), a few other papers study taxes in developing countries utilizing administrative data. A closely related paper is that of Bachas and Soto (2015), who estimate the distortions caused by the peculiar Costa Rican corporate income tax system where the average tax rate increases at certain income thresholds. Using additional data from tax audits, they argue that the response to these tax notches is

\footnotetext{
2 More generally, reporting responses are less detrimental to welfare, compared to changes in the extent of real economic behavior. For example, part of the evasion/avoidance responses typically entails transfers to other agents in the economy or transferring of reported income over time between different tax years, and thus the welfare costs of taxation are smaller if evasion/avoidance drives the response rather than real economic behavior (see, e.g., Chetty 2009).

3 See Fisman and Svensson (2007) for an early study using survey data to examine the impacts of taxes (and bribe payments) on firm growth.
} 
almost entirely due to evasion, mostly cost overreporting. The Costa Rican and Pakistani notch-based tax systems are, of course, highly interesting, but since they are not typically applied elsewhere, seeking additional evidence on the impacts of more traditional types of taxes on individual and corporate behavior in developing countries is of great importance and holds the promise of considerable external validity.

In addition, Carrillo et al. (2017) and Pomeranz (2015) use administrative taxpayer data from Ecuador and Chile and combine these data with field or natural experiments to examine how tax evasion can be combated in developing countries. The focus in these types of experimental papers, surveyed by Mascagni (2017), is different from ours: They concentrate on avoidance and evasion rather than studying more conventional sufficient statistics for determining overall behavioral responses. There is no doubt that experimental evidence of the possibilities for influencing evasion is of key importance, but it remains equally useful to know more about the overall extent of the distortions that current tax systems induce.

The paper proceeds as follows: Sect. 2 presents the institutional framework of the South African corporate tax system. Section 3 outlines the conceptual background for the analysis and the empirical strategy we use in the estimations. Section 4 describes the data and includes some descriptive material. The results are presented in Sects. 5, and 6 concludes.

\section{Institutions}

\subsection{South Africa}

South Africa is an upper-middle-income country (GNI per capita was USD 6,800 in 2014) and a member of the BRICS (Brazil, Russia, India, China and South Africa), a group of major emerging economies. According to the figures in the dataset of Prichard et al. (2014), total tax revenue including social security payments was $27 \%$ of GDP in 2012, whereas the average for upper-middle-income countries was $23 \%$. In particular, revenues from corporate income tax are a significant source in South Africa, $5.5 \%$ of GDP as opposed to $3 \%$ in the comparison group of other upper-middle-income countries. Taxes on goods and services, including revenue from value-added tax, stood at $10 \%$ and $9 \%$ of GDP in South Africa and other upper-middle-income countries, respectively.

While the revenue-raising capacity in South Africa appears stronger than in other developing countries, the need for revenue is also significant in order to enable the government to finance social protection and other activities which are needed to combat the high inequality level in society. ${ }^{4}$ The high inequality is reflected in a considerable share of absolutely poor people, with a headcount ratio of approximately $17 \%$ using the new 1.9 USD per day poverty line of the World Bank. ${ }^{5}$ Finally, in comparison with other countries in sub-Saharan Africa, in South Africa the informal sector is

\footnotetext{
4 The Gini coefficient for consumption stood at 0.64 according to Leibbrandt et al. (2016).

5 Source: World Bank, http://data.worldbank.org/indicator/SI.POV.DDAY?locations=ZA (accessed 22.3.2017).
} 
estimated to comprise a smaller share of the overall economy. According to Statistics South Africa (2015), the share of informal employment out of total non-agricultural employment was $16 \%$, whereas the same share is close to or above $50 \%$ in seven other sub-Saharan African countries for which there are data in ILO (2014). A recent study by Medina et al. (2017) finds that the GDP share of the informal sector is around $20 \%$ in South Africa, which is one of the lowest shares in Africa. For most other African countries, the GDP share of the informal sector is in the range of 40-60\%.

\subsection{Corporate income tax system}

The South African Revenue Service (SARS) is the tax authority of the Republic of South Africa, and among other taxes, it collects corporate income tax (CIT). Resident companies, with the exception of gold-mining companies, small-business corporations and micro-businesses, are currently subject to a flat tax rate of $28 \%$. In addition, dividends are taxed at the shareholder level at a $15 \%$ rate.

The focus of this paper is on small-business corporations (SBC). The South African government has implemented a graduated, progressive corporate income tax rate schedule for small businesses in order to stimulate economic activity. In order to be eligible for this graduated tax regime, the following conditions must be met:

- Company shareholders or members of the cooperative or close corporation must be natural persons

- Gross income should not exceed R20 million for the year of assessment. The threshold was R14 million before 2013.

- The shareholders or members are not allowed to own shares or any interest in the equity of any other company, except in companies specifically permitted

- A limit of $20 \%$ is placed on the amount of non-capital receipts and accruals as well as capital gains that can be collectively classified as investment income and income from rendering a personal service

- Entities classified as a personal service provider as defined in the Fourth Schedule of the Income Tax Act and Individual Policyholder Funds (IPFs) of long-term insurers do not qualify for the SBC regime

The tax rates and threshold values of the small-business income tax regime are presented in Table 1. In the years we examine (2010-2013), there have been two baseline threshold values: around R60,000 of taxable corporate income, where the CIT rate jumps from 0 to $10 \%$, and R300,000, where the CIT rate further increases to $28 \%$. These tax rate thresholds have changed over the years. The lower threshold has increased annually by approximately R3,000. The upper threshold has remained constant even in nominal terms, but it was increased to R350,000 in the beginning of April 2012. Also, the lower rate was slightly reduced from $10 \%$ to $7 \%$ at the same time. In addition, starting from 2014, a third kink was introduced, but the data we use do not cover the years when this new system has been in place. ${ }^{6}$

In general, corporate taxable income in a tax year includes all generated income (e.g., business profits and interest payments), less non-capital expenses, allowable

6 The progressive CIT schedule has been operational since 2001, but the number of brackets has increased and the rates and thresholds have changed over time. 
Table 1 Corporate income tax rates for small-business corporations

\begin{tabular}{llc}
\hline Assessment period & $\begin{array}{l}\text { Taxable corporate } \\
\text { income (rand) }\end{array}$ & $\begin{array}{l}\text { Marginal tax rate } \\
\text { (MTR) }(\%)\end{array}$ \\
\hline $01 / 04 / 2009-31 / 03 / 2010$ & R1 - R54,200 & 0 \\
& R54,201 - R300,000 & 10 \\
& R300,001 and above & 28 \\
$01 / 04 / 2010-31 / 03 / 2011$ & R1 - R57,000 & 0 \\
& R57,001 - R300,000 & 10 \\
$01 / 04 / 2011-31 / 03 / 2012$ & R300,001 and above & 28 \\
& R1 - R59,750 & 0 \\
$01 / 04 / 2012-31 / 03 / 2013$ & R59,751 - R300,000 & 10 \\
& R300,001 and above & 28 \\
& R1 - R63,556 & 0 \\
& R63,557 - R350,000 & 7 \\
\hline
\end{tabular}

The marginal corporate income tax rates in different assessment periods for firms that are eligible for the small-business corporation (SBC) tax regime

deductions and reserves and incurred losses. A tax loss incurred in any business activity in earlier tax years may be carried forward indefinitely and set off against future corporate income (provided that the company remains active during the whole assessment period). Naturally, if a firm's owners pay themselves salaries, they would need to pay the progressive earned income tax on this income. The CIT thresholds and the wage income tax rate kink points are not aligned, creating room for income-shifting incentives between salaries and dividends. Unfortunately, matched owner and corporate income tax data are not available for South Africa. While regrettable, such data are not necessarily available in many high-income countries either. Nevertheless, we tentatively characterize the income-shifting margin by studying the total wages paid by the firm, including both the owners' wages and wages paid to employees. We discuss this in detail in Sect. 5.3.

In addition to these tax incentives, micro-businesses with a turnover below R1 million have been able to choose whether they are taxed according to the CIT schedule or according to a presumptive turnover tax, where the tax is levied using a progressive turnover scale. ${ }^{7}$ However, data on turnover tax returns are not available for research purposes, and we cannot therefore examine responses to the turnover tax. This can be considered a minor issue, since the turnover tax has not been very popular. The reasons include lack of willingness by informal firms to voluntarily register as taxpayers and lack of knowledge of the system. As an illustration of this, revenue collected from the turnover tax in the 2014-2015 financial year amounted to only R17.5 million, or $0.2 \%$ of total tax revenue. The corresponding figure for revenue collected from other

\footnotetext{
7 In the fiscal year ending 2012, the marginal tax rates were: $0 \%$ for turnover up to R 150,$000 ; 1 \%$ on the amount exceeding R150,000 but not exceeding R300,000; $2 \%$ of the amount exceeding R300,000 but not exceeding R500,000; 4\% of the amount exceeding R500,000 but not exceeding R750,000; and 6\% of the amount exceeding R750,000.
} 
companies was R185 billion (18.7\% of total tax revenue), of which 1.6 billion came from SBCs.

All entities classified as a company or close corporation need to register as a taxpayer within 21 business days of becoming liable for income tax or liable for submitting a tax return. All incorporated companies, excluding entities that have opted to make use of the turnover tax regime, have to complete the Income Tax Return for Companies (previously IT14 and now ITR14 form) and submit it within 12 months of the end of the tax year. Finally, the financial year of a firm can differ from the tax assessment period. The end date of the tax assessment period defines the tax schedule applied to firms. As an example, 2012 tax rates (rates in effect from April 1, 2011 to March 31, 2012) are applicable to SBCs with financial years ending between April 1, 2011 and March 31, 2012, and 2013 tax rates (rates in effect from April 1, 2012 to March 31, 2013) are applicable to SBCs with financial years ending between April 1, 2012 and March 31, 2013. In the data, we observe the tax year according to which the taxable income of the firm is taxed.

\section{Conceptual framework}

\subsection{Firm responses to the graduated CIT schedule}

Next, we present a simple model of how firms can respond to corporate income taxes. This model will also help us to understand the anatomy behind the response: What part of the potential response is due to changes in real economic activity and what represents merely reporting behavior.

The utility of the owner(s) of a small firm ${ }^{8}$ is given by

$$
U=y-c_{i}(y)-e_{i}(y)-T-\phi_{y}\left(\delta_{y}\right)-\phi_{c}\left(\delta_{c}\right)-\phi_{a}\left(\delta_{a}\right),
$$

where $c_{i}(y)$ depicts the minimum costs needed to reach real gross sales $y$, and $c_{i}^{\prime}>$ $0, c_{i}^{\prime \prime}>0$. The effort of the owner needed to reach $y$ is denoted by $e_{i}(y)$, and $e_{i}^{\prime}>0, e_{i}^{\prime \prime}>0$. The main difference between $c_{i}(y)$ and $e_{i}(y)$ is that the latter is assumed to be non tax-deductible. $T$ denotes the corporate taxes paid, which we discuss in more detail below. In order to reduce tax payments, the firm owner can hide part of the taxable sales income, $\delta_{y}$, at a cost of $\phi_{y}\left(\delta_{y}\right)$ and also exaggerate reported costs at a cost of $\phi_{c}\left(\delta_{c}\right)$, where $\delta_{c}$ depicts the fabricated costs. The owner can also utilize various tax avoidance and tax-planning measures to reduce CIT payments in a current tax year, such as loss carryforward, at a cost of $\phi_{a}\left(\delta_{a}\right)$, where $\delta_{a}$ denotes the avoided amount.

The main focus of our study is on the behavioral responses caused by $T$. The corporate income tax function is $T=\tau_{p} \mathrm{TI}+\Delta \tau_{p}\left(\mathrm{TI}-\mathrm{TI}^{*}\right) \cdot \mathbf{1}\left(\mathrm{TI}>\mathrm{TI}^{*}\right)$, where $\mathrm{TI}$ is corporate taxable income (corporate income tax base), $\mathrm{TI}^{*}$ is the corporate tax kink point and $\tau_{p}$ is the marginal corporate tax rate below the kink and $\tau_{p}+\Delta \tau_{p}$ above the kink. Corporate taxable income in a tax year is determined by

\footnotetext{
8 We assume that firm owners make all the relevant firm-level decisions. However, for simplicity, in the remainder of the paper, we assume that firms respond to tax incentives.
} 


\section{Bunching at the kink point}

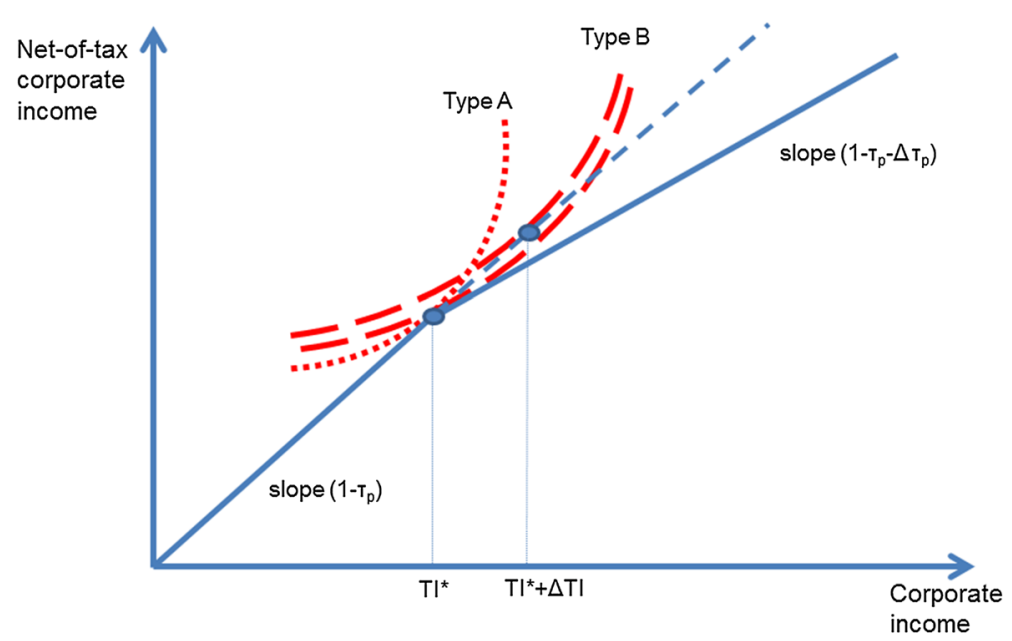

Fig. 1 Bunching at corporate income tax rate kink. Notes Figure demonstrates bunching behavior in a graduated corporate income tax rate schedule. The solid lines illustrate the tax rates below and above the kink point $\mathrm{TI}^{*}$. The dashed curvy lines represent the indifference curves of different types of firms and firm owners

$$
\mathrm{TI}=y-c_{i}(y)-\delta_{y}-\delta_{c}-\delta_{a}
$$

First, consider a flat tax regime where $\Delta \tau_{p}=0$. The firm owner maximizes utility with respect to sales $y$ and the extent of evasion $\left(\delta_{y}, \delta_{c}\right)$ and avoidance $\left(\delta_{a}\right)$. This yields the following first-order conditions: $\left(1-c_{i}^{\prime}(y)\right)\left(1-\tau_{p}\right)=e_{i}^{\prime}(y)$, and $\phi_{y}^{\prime}\left(\delta_{y}\right)=\phi_{a}^{\prime}\left(\delta_{a}\right)=$ $\phi_{c}^{\prime}\left(\delta_{c}\right)=\tau_{p}$. The reporting effects imply that the sales and costs of the firm can be under- or overreported and that firms can utilize legal avoidance measures to reduce reported corporate income, taking into account the (marginal) costs of these various measures.

Next, we consider firm responses to the kink point $\mathrm{TI}^{*}$, where the tax rate increases from $\tau_{p}$ to $\tau_{p}+\Delta \tau_{p}$ in a discontinuous manner. Intuitively, when the kink point is introduced, firms have incentives to adjust their corporate taxable income such that they locate exactly at the kink point, as marginal net-of-tax profits are lower above the kink. Therefore, if the average tax responsiveness of firms is significant, this will lead to an excess mass of firms located at the kink point, compared to a smooth counterfactual distribution that would prevail in the absence of the kink. This excess bunching can be translated into a local tax rate elasticity, explained in more detail in Sect. 3.2.

The bunching framework is illustrated in Fig. 1. Firms originally at or below TI* do not change their behavior when the kink is introduced (Type A), but a fraction of firms located above $\mathrm{TI}^{*}$ will bunch at the threshold (Type B). The extent of the bunching response depends on the underlying responsiveness to the corporate income tax rate, illustrated by the dashed indifference curves in the figure.

Bunching firms can reduce their reported corporate income either by lowering their true level of production or by engaging in tax evasion or avoidance measures. 
Responses to the kink point along the real behavioral margin (production responses) are likely to produce a cluster of firms around the kink point, rather than a sharp spike exactly at $\mathrm{TI}^{*}$. This is due to the fact that real sales and expenses are likely to be uncertain and are at least to some extent imperfectly controlled by the firm because of, for example, unpredictable demand-side effects and other frictions in the market. In contrast, various reporting responses are likely to be less scattered around the kink, as they involve less uncertainty and can be more precisely governed by the firm at the end of the tax year. Therefore, following Best et al. (2015), studying the sharpness of bunching behavior can provide initial evidence of the nature of the responses. ${ }^{9}$

Finally, we can modify Eq. (2) to distinguish between different types of responses that comprise the overall change in taxable corporate income due to a change in the corporate income tax rate:

$$
\frac{\mathrm{dTI}}{\mathrm{d}\left(1-\tau_{P}\right)}=\left[1-c_{i}^{\prime}(y)\right] \frac{\mathrm{d} y}{\mathrm{~d}\left(1-\tau_{P}\right)}-\frac{\mathrm{d} \delta_{y}}{\mathrm{~d}\left(1-\tau_{P}\right)}-\frac{\mathrm{d} \delta_{c}}{d\left(1-\tau_{P}\right)}-\frac{d \delta_{a}}{\mathrm{~d}\left(1-\tau_{P}\right)}
$$

This formula further emphasizes that the overall response is characterized by both the real production elasticity and various reporting elasticities: $\varepsilon_{(1-\tau)}^{\mathrm{TI}}=$ $\left(\varepsilon_{(1-\tau)}^{y}, \varepsilon_{(1-\tau)}^{\delta_{y}}, \varepsilon_{(1-\tau)}^{\delta_{c}}, \varepsilon_{(1-\tau)}^{\delta_{a}}\right)$, where $\varepsilon_{(1-\tau)}^{\mathrm{TI}}=\frac{\mathrm{dTI}}{\mathrm{d}\left(1-\tau_{p}\right)} \frac{\left(1-\tau_{p}\right)}{\mathrm{TI}}$ is the elasticity of corporate income and $\varepsilon_{(1-\tau)}^{\delta_{y}}, \varepsilon_{(1-\tau)}^{\delta_{c}}$ and $\varepsilon_{(1-\tau)}^{\delta_{a}}$ denote various reporting elasticities. In our empirical analysis, we utilize variation created by changes in the location of the kinks and study firm-level characteristics in the neighborhood of the kink points to offer suggestive evidence of different types of responses.

\subsection{Empirical strategy}

We estimate the excess mass at corporate income tax kinks following earlier bunching literature (e.g., Chetty et al. 2011). First, we estimate a counterfactual corporate income distribution that would exist in the absence of the kink point. The behavioral response to the kink point, i.e., the excess mass of firms at the kink, is then estimated by relating the actual number of firms around the kink point to this counterfactual density.

The counterfactual density is estimated by fitting a flexible polynomial function to the observed distribution, excluding an area around the kink point in the observed distribution:

$$
c_{j}=\sum_{i=0}^{p} \beta_{i}\left(\mathrm{TI}_{j}\right)^{i}+\sum_{i=\mathrm{TI}_{L}}^{\mathrm{TI}_{H}} \eta_{i} \cdot \mathbf{1}\left(\mathrm{TI}_{j}=i\right)+\varepsilon_{j}
$$

where $c_{j}$ is the count of firms in bin $j$, and $\mathrm{TI}_{j}$ denotes the corporate income level in bin $j$. The order of the polynomial is denoted by $p$. The fitted values for the counterfactual density are given by $\hat{c}_{j}=\sum_{i=0}^{p} \beta_{i}\left(\mathrm{TI}_{j}\right)^{i}$, and $\left[\mathrm{TI}_{L}, \mathrm{TI}_{H}\right]$ denotes the area where the kink point affects the behavior of firms which need to be excluded when estimating the counterfactual density. As discussed above, we hypothesize that responses along

\footnotetext{
9 According to Best et al. (2015), sharp bunching and the fact that the excess mass closely follows the changes in the kink point provide evidence of evasion-driven responses in their setting.
} 
the real economic margin produce more scattered responses around the kink than avoidance or evasion responses would, due to the larger inherent uncertainty and more imperfect control over real economic variables such as demand-side effects and realized costs.

Excess bunching is estimated by relating the actual number of firms in the excluded range to the estimated counterfactual density in the same region:

$$
\hat{b}\left(\mathrm{TI}^{*}\right)=\frac{\sum_{i=\mathrm{TI}_{L}}^{\mathrm{TI}_{H}}\left(c_{j}-\hat{c}_{j}\right)}{\sum_{i=\mathrm{TI}_{L}}^{\mathrm{TI}_{H}} \hat{c}_{j} / N_{j}}
$$

where $N_{j}$ is the number of bins within $\left[\mathrm{TI}_{L}, \mathrm{TI}_{H}\right]$.

We follow a standard method in the literature where the excluded range is determined visually based on the shape of the observed distribution. We define the upper limit to be as far from the kink point as the lower limit is. We conduct several robustness checks to study the sensitivity of our results by varying the choice of the excluded range and the order of the polynomial.

The excess bunching estimate can be translated into a local corporate tax rate elasticity estimate. The elasticity at the kink point is derived using the following formula (see, e.g., Bastani and Selin 2014):

$$
{ }^{\varepsilon} \mathrm{TI}^{*}=\frac{\mathrm{dTI}}{\mathrm{d}\left(1-\tau_{p}\right)} \frac{1-\tau_{p}}{\mathrm{TI}} \simeq \frac{\hat{b}\left(\mathrm{TI}^{*}\right)}{\mathrm{TI}^{*} * \hat{c} * \log \left(\frac{\left(1-\tau_{P}\right)}{\left(1-\tau_{P}-\Delta \tau_{P}\right)}\right)},
$$

where $\tau_{p}$ is the corporate income tax rate that jumps at a kink point $\mathrm{TI}^{*}$ from $\tau_{P}$ to $\tau_{P}+\Delta \tau_{P}$ and $\widehat{c}$ depicts the counterfactual density at the kink in the absence of the kink point. However, it can be the case that not all firm owners necessarily react to changes in marginal CIT rates. As discussed in the bunching literature, this non-responsiveness can stem from various behavioral frictions, such as inattention or unawareness (see, e.g., Kleven 2016). This implies that local elasticity estimates derived from observed bunching at kink points might only represent a lower bound of the overall responsiveness to tax incentives.

Finally, as is customary in the literature, we calculate standard errors for all the estimates using a residual-based bootstrap procedure. We generate a large number of distributions by randomly resampling the residuals from Eq. (4) with replacement and generate a large number of new estimates of the counterfactual density based on the resampled distributions. The standard errors for each estimate are defined as the standard deviation in the distribution of the estimate.

\section{Data and descriptive statistics}

The data used for this paper were obtained as part of the firm-level research program that forms part of the collaborative effort between the National Treasury of South Africa, the South African Revenue Service (SARS) and the World Institute for 
Table 2 Summary statistics for the SBC sample

\begin{tabular}{llllll}
\hline Stats & Corp. taxable income & Sales & Cost of sales & Labor costs & Expenditure \\
\hline Mean & 196,760 & $4,341,774$ & $1,237,140$ & 452,140 & $2,252,365$ \\
SD & 392,073 & $676,883,081$ & $2,500,267$ & 736,191 & $3,289,287$ \\
N & 221,492 & 221,492 & 221,492 & 221,492 & 221,492 \\
\hline Stats & & Total balance sheet & Equity & Capital \\
\hline Mean & $17,293,720$ & $1,223,049$ & $10,076,934$ \\
SD & $2,959,002,234$ & $329,476,079$ & $2,416,482,358$ \\
N & 221,492 & 221,492 & 221,492 \\
\hline
\end{tabular}

The table includes descriptive statistics for firms qualifying for the SBC regime in 2010-2013 (in Rands). Expenditure includes all costs related to the firms' operations, including labor costs

Development Economics Research of the United Nations University (UNU-WIDER). This program has made it possible for the first time to perform research on highly disaggregated firm-level tax data over a multi-year time frame in Africa.

The firm-level information was extracted from the SARS core systems by the SARS Revenue Planning, Analysis, Research and Reporting (RPARR) division. An administrative database is currently available from 2009 to 2013, but according to the SARS appraisal, the data for 2009 are incomplete and may be unrepresentative. Thus, in this paper, we concentrate on the years 2010-2013, and in our main analysis restrict the sample to those firms that are taxed according to the $\mathrm{SBC}$ regime discussed above. The tax regime status (SBC/non-SBC) is directly observable in the administrative data.

Table 2 provides the summary statistics for the SBC sample used to estimate the responses to the graduated CIT schedule. Note that while there is a lot of diversity in the firms in the data, for the actual statistical analysis we focus on firms that are relatively close to the kink points and are therefore in general more homogeneous in terms of corporate income, sales and expenses.

Figure 2 illustrates the distribution of corporate taxable income for small businesses in 2010-2013 in the neighborhood of the kink points. The vertical lines depict the kink points in the CIT schedule. The lower kink points (around R60,000) have been adjusted annually according to the inflation rate. The upper kink point, which in earlier years stood at R300,000, was raised to R350,000 in 2013.

It is evident already from Fig. 2 that tax incentives matter. The distributions are otherwise rather smooth, but there is a clear concentration of firms close to the kink points, and the extent of this concentration appears to be large. In the following analysis, we study this bunching behavior in more detail. In addition, the distributions of various firm-level factors, such as equity and expenditures, are in general smooth and well behaved, which underlines the high quality of the South African administrative data. This finding is not surprising given the relatively large extent of formalization in the South African business sector, in comparison with many other emerging economies. 

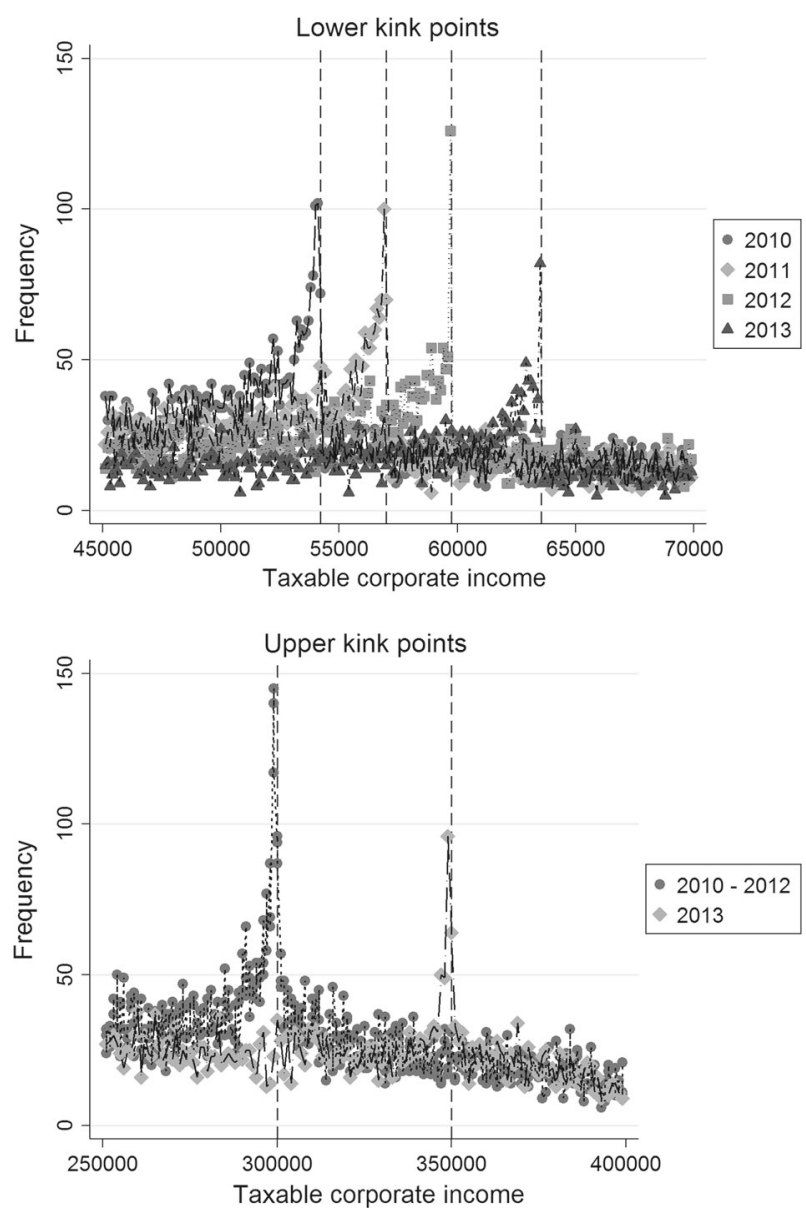

Fig. 2 Distributions of corporate taxable income for small businesses around the CIT kink points, 20102013. Notes Figure shows the distributions of corporate taxable income in bins of R100 (lower kink) and $\mathrm{R} 1,000$ (upper kink) in the neighborhoods of the CIT kink points in 2010-2013. The lower kink points are R54,200, R57,000, R59,740 and R63,556 in 2010, 2011, 2012 and 2013, respectively. The upper kink point was R300,000 in 2010-2012 and R350,000 in 2013

\section{Results}

\subsection{Baseline results}

The upper and lower panels of Fig. 3 show the distributions of corporate taxable income (solid line) and the counterfactual distributions (dashed line) around the lower and upper tax rate thresholds in bins of R1,000 using pooled data for 2010-2013. The threshold is marked with dashed vertical lines, and the distributions for each year are centered such that zero denotes the kink point. Thus, the $x$-axis denotes the distance from the kink point. The excluded region $\left[\mathrm{TI}_{L}, \mathrm{TI}_{H}\right]$ in the estimation of the counterfactual is marked with solid vertical lines. 
Lower kink, 2010-2013

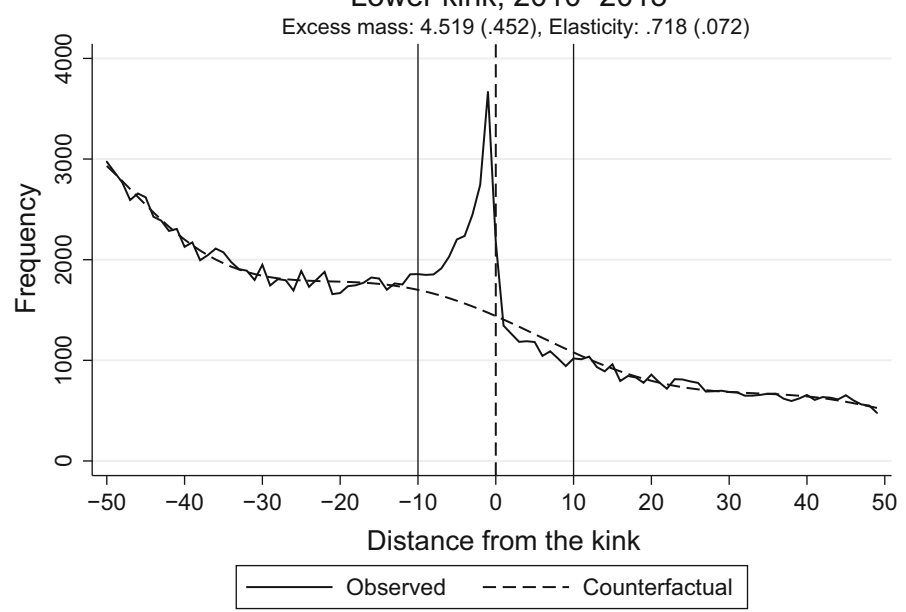

Upper kink, 2010-2013

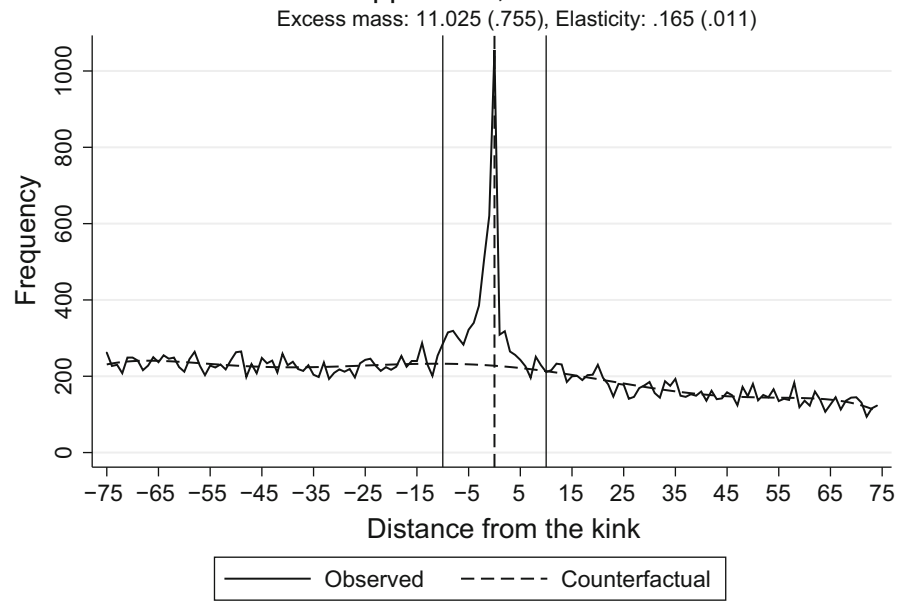

Fig. 3 Bunching at the corporate income tax rate kinks, 2010-2013. Notes Figure shows the distributions of corporate taxable income and the counterfactual distributions relative to the lower and upper corporate tax rate kinks in bins of R1,000 and the excess mass and local corporate income elasticities at the kink points with bootstrapped standard errors using pooled data for 2010-2013. The threshold is marked with dashed vertical lines. The excluded region in the estimation of the counterfactual is marked with solid vertical lines

Figure 3 shows that the excess bunching is striking at both of these CIT kinks. A significant proportion of firms locate themselves around the thresholds. The estimates for excess bunching are large and strongly statistically significant. Consequently, the implied elasticity estimates are also relatively large, 0.72 and 0.17 for the lower and upper kink points, respectively. However, as mentioned above, it could be that not all firm owners necessarily react to changes in marginal rates due to, for example, inattention or other frictions (see Kleven 2016). Therefore, these estimates can be 
seen as lower bounds. Nevertheless, these results show that the corporate income tax kinks clearly affect the reported corporate income of small businesses. ${ }^{10}$

Figure 7 in Appendix shows the density distributions of corporate taxable income for both SBC and non-SBC firms around the lower and upper kink points. As may be expected, there is no bunching at either of the thresholds among non-SBC firms that face a flat tax rate of $28 \%$. The distributions of non-SBC firms around the thresholds resemble the estimated counterfactual distributions for the SBC firms in Fig. 3, particularly in the neighborhood of the kink points. This further supports the local estimation results above. Furthermore, Table 4 in Appendix shows the robustness checks for the bunching results when we vary the choice of the excluded range and the order of the polynomial. Overall, the point estimates for excess bunching vary somewhat when these choices are altered, but the main conclusion of the significant excess mass at the kink points is not sensitive to these choices. ${ }^{11}$ In addition, Fig. 8 in Appendix implies that none of the typical industries (manufacturing, services, construction, trade, financial services) are overrepresented in the bins just around the kink points, compared to other bins in the neighborhood of the thresholds. This shows that bunching responses are not predominantly associated with firms operating in particular industries.

One particular difference between the observed responses to the upper and lower kinks emerges from Fig. 3: The response to the lower kink occurs below the kink point, whereas following the theoretical framework, firms scatter around both sides of the upper kink point. In general, there is no obvious reason to assume bunching only below the threshold at the lower kink point. For example, there are no changes in reporting requirements or other regulations when the lower threshold is exceeded that would explain the nature of the response. However, the payment of a positive tax above the threshold could induce a small additional compliance cost for firms, which could cause them to cluster below the kink. Also, firms might mistakenly believe that there would be a tax notch rather than a tax rate kink at the threshold, which could imply that the estimated elasticity is upward biased. However, we cannot offer any causal evidence to support these behavioral hypotheses. ${ }^{12}$

Furthermore, since increasing reported corporate taxable income below the lower kink induces no tax payments, it could be that firms increase their reported income

\footnotetext{
10 Alternatively, we can calculate the elasticities using the changes in the effective dividend tax rate of the owner at the kink point. The effective dividend tax rate is defined as $\tau_{p}+\left(1-\tau_{p}\right) * \tau_{D}$, where $\tau_{D}$ denotes the flat dividend tax rate $(15 \%)$. Using these effective net-of-tax rates in the denominator of the elasticity formula does not change the results significantly, as the elasticities for the lower and upper kink points are $0.718(0.077)$ and $0.165(0.012)$.

11 When studying individual income tax rate kink points in Denmark, Chetty et al. (2011) iteratively adjust the counterfactual density above the bunching window such that it includes the excess mass at the kink, making the estimated counterfactual density equal to the observed density. As an additional robustness check, we follow this procedure and estimate the excess mass to be 3.38 and 9.18 at the lower and upper kink points (respectively) using a seventh degree polynomial and a bunching window of $+/-\mathrm{R} 10,000$. The counterfactual density is adjusted up to the 50th and 75th income bin for the lower and upper kink points, respectively. Overall, this procedure somewhat reduces the excess mass estimates, but does not change the conclusion of significant behavioral responses to the CIT kink points.

12 In addition, the elasticity estimate is larger at the lower kink point even though the excess mass is smaller than at the upper kink. This is mainly due to the fact that the relative change in the net-of-tax rate is less than half at the lower kink point compared to the upper kink. Therefore, in addition to potential behavioral aspects, it could be that smaller firms are inherently more responsive to tax rates than larger firms.
} 
in a given tax year in order to benefit from the zero tax rate. This intertemporal tax avoidance channel would create excess mass only on the left of the kink, as observed in Fig. $3 .^{13}$ In addition, one further driver of the hump-shaped distribution below the lower kink could be the small annual increases in the location of the kink point. This could create a more scattered response below the kink if some firms do not adjust to these small changes immediately. We discuss these channels in more detail in Sects. 5.2 and 5.3.

In the remainder of the paper, we primarily focus on behavioral responses to the upper CIT kink. A distinctive and clear change in the location of the upper kink in 2013 provides useful variation to study firm responses to tax incentives, and in particular, the potential mechanisms behind behavioral responses (real and reporting responses). We discuss this issue in detail in Sect. 5.2.

Finally, in addition to CIT kink points, firms could respond to the SBC regime eligibility rules by adjusting their gross income such that it does not exceed the eligibility threshold, which was R14 million in 2010-2012 and was increased to R20 million in 2013. By locating below the threshold, corporate income would be taxed at the progressive CIT schedule, in contrast to the flat tax rate of $28 \%$ for total taxable corporate income. Thus, firms could reduce their average corporate tax payments by locating below the SBC threshold even if their taxable income exceeds the upper CIT kink point, as only corporate income exceeding the kink is subject to the $28 \%$ tax rate.

Figure 9 in Appendix shows that the responses to the SBC eligibility threshold are negligible. Nevertheless, there is visible and statistically significant excess mass at this threshold in 2010-2012 (0.20 (0.06)), but the extent of the response is very small, at least when compared to the sharp and distinctive responses to the CIT kinks. One plausible explanation for the small response is that only firms with a reported profit rate of less than $2.1 \%$ would be able to bunch below the upper CIT kink if they simultaneously bunch at the SBC gross income threshold. In addition, the monetary benefit of locating at the threshold in terms of tax savings falls as the profit rate increases, which reduces the incentives to actively respond to this threshold. ${ }^{14}$ Furthermore, responding to this threshold by avoidance or evasion could be more difficult compared to CIT kinks, as only gross income affects the eligibility rule, whereas corporate taxable income can also be adjusted utilizing reported costs and various avoidance measures.

\subsection{Real versus reporting responses}

The bunching results above show that firms respond very actively to tax schedule discontinuities, implying notable responsiveness to tax incentives. However, these results do not give us direct evidence of how firms actually respond, as the crosssectional excess bunching estimate is a function of both real elasticity and reporting elasticity components, $\hat{b}\left(\mathrm{TI}^{*}\right)=\left(\varepsilon_{(1-\tau)}^{y}, \varepsilon_{(1-\tau)}^{\delta_{y}}, \varepsilon_{(1-\tau)}^{\delta_{c}}, \varepsilon_{(1-\tau)}^{\delta_{a}}\right)$. Next, we utilize the shape of the bunching responses and the changes in the location of the kink points to

\footnotetext{
13 We thank an anonymous reviewer for pointing out this type of mechanism.

14 For example, for a firm with a R1 million profit, the monetary gain of bunching at the SBC eligibility threshold (R20 million) is 6\% relative to total profits, whereas for a firm with a R5 million profit, the gain is only $1.2 \%$ relative to profits.
} 


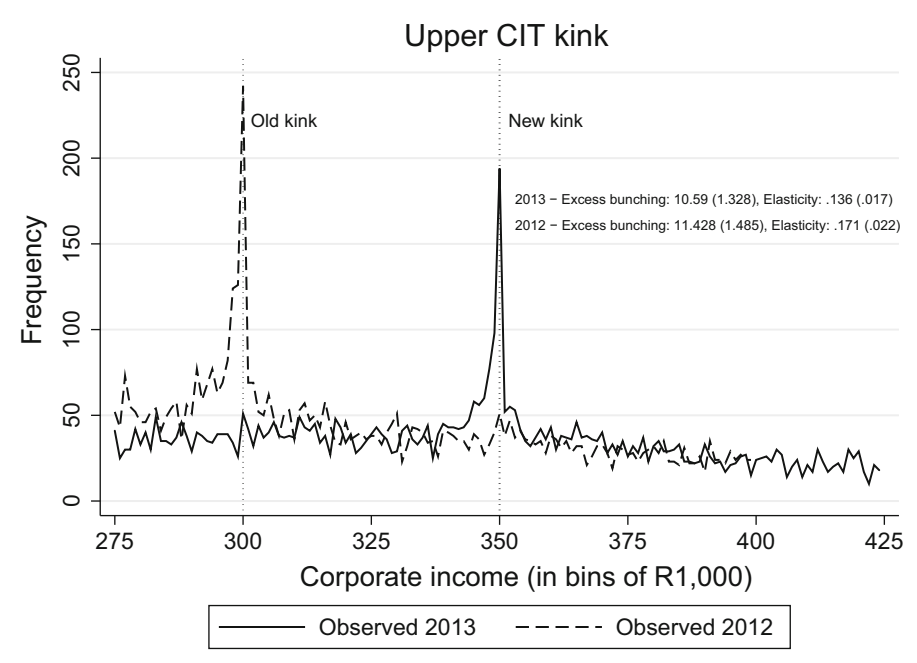

Fig. 4 Change in the location of the upper CIT kink point. Notes Figure shows the observed distributions of corporate taxable income around the upper corporate tax rate kink in bins of R1,000, and the excess mass and local corporate income elasticities at the kink point with bootstrapped standard errors in 2012 and 2013. The kink points in different years are marked with dashed vertical lines. The upper kink point was at $\mathrm{R} 300,000$ in 2012 and R350,000 in 2013

study the role of different types of responses. However, as it is difficult to obtain direct causal evidence of the significance of various components given the tax rate variation and available data, the evidence presented in this section needs to be interpreted as suggestive.

\subsubsection{Change in the location of the upper kink point}

Our main evidence comes from the change in the location of the upper kink point, illustrated in Fig. 4. First, the figure shows that firms bunched very sharply and at a similar magnitude at the upper kink point in both 2012 and 2013. Second, the excess mass at the old kink point $(\mathrm{R} 300,000)$ disappears immediately when the kink point is relocated to R350,000 in 2013, implying that firms immediately adjust their corporate taxable income to a new level after the reform. These instant changes give us our first piece of suggestive evidence of reporting responses. As discussed above, real responses would likely require adjustments along many dimensions that are subject to considerable uncertainty, such as realized expenses and labor input, other production investments and demand-side responses. To further support this reasoning, the overall bunching responses at the upper kink are strikingly sharp both before and after 2013 . This evidence is also more in line with reporting responses than real responses, which would entail a more scattered response around the kink point given the larger inherent uncertainty in many real economic outcomes.

To study the upper kink in more detail, Fig. 5 shows the distribution around the kink point in 2013 with and without those firms that bunched at the kink in 2012, a year before it was relocated. The figure highlights that a large fraction of the response 


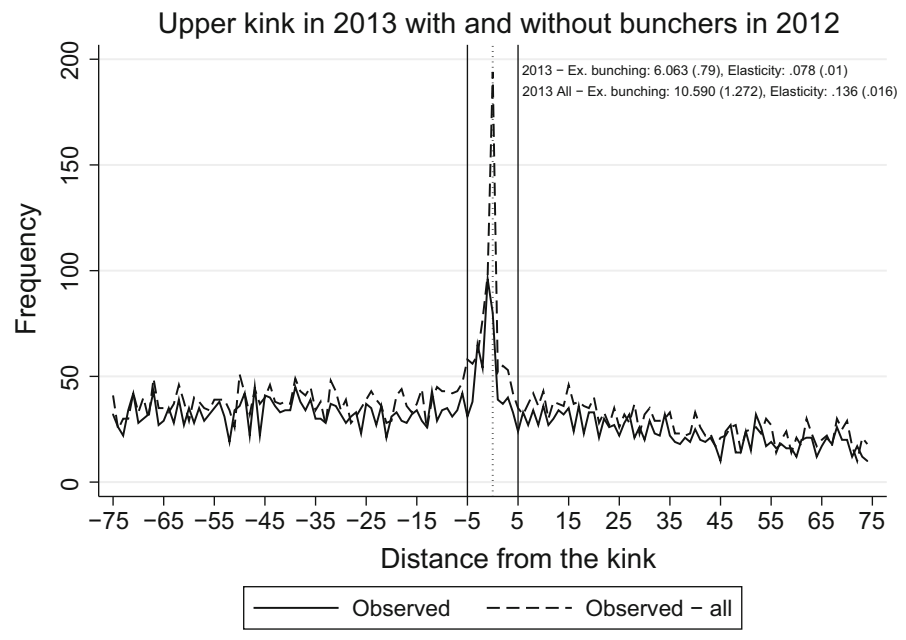

Fig. 5 Excess bunching at the upper CIT kink in 2013 with and without the firms that bunched at the kink in 2012. Notes Figure shows the observed distributions of corporate taxable income relative to the upper corporate tax rate kink in bins of R1,000, and the excess mass and local taxable corporate income elasticities at the kink point with bootstrapped standard errors using data for 2013. The figure includes the distributions and estimates for the entire sample and the sample excluding the firms that bunched at the old corporate tax rate at $\mathrm{R} 300,000$ kink in 2012

in 2013 comes from those firms that also bunched in 2012. The excess mass estimate falls from 10.6 to 6 when excluding bunchers in the previous year. This implies that a large share of firms that bunched at the kink in 2012 increased their taxable corporate income by approximately 17\% from around R300,000 to around R350,000 to match the new kink point. In comparison, the average annual growth rate of corporate income was approximately $1.5 \%$ for all firms around the kink $(+/-\mathrm{R} 75,000)$. Furthermore, Fig. 10 in Appendix shows that a large fraction of firms (30-35\%) that located at the kink in 2013 were those that bunched at the R300,000 kink point in 2012 or 2011. ${ }^{15}$ In the following subchapters, we study the reporting behavior of bunching firms and those firms that exactly follow the changes in the location of the kink point to further characterize the potential mechanisms behind the observed responses to the CIT kinks.

\subsubsection{Responses of relocating firms versus other firms}

Next, following the evidence above, we characterize the extent of the feasible real responses of firms that follow the change in the location of the upper kink point. In order to motivate our analysis below, consider a firm for which $\mathrm{d} \delta_{y}=\mathrm{d} \delta_{c}=\mathrm{d} \delta_{a}=0$ in Eq. 3, responding to an increase in the kink point. For this type of firm, an increase in

\footnotetext{
15 In addition, Fig. 11 in Appendix shows that the same firms tend to avoid moving from the kink point over time, both at the upper and lower CIT kink points. The figure shows that the persistence rate of firms staying within a particular corporate income bin from one year to another is larger at the kink point than elsewhere in the distribution around it. This provides additional evidence that firms adjust their behavior with respect to the kink point over time, which is consistent with the significant corporate income responses when the thresholds were increased.
} 
corporate income is only possible via a corresponding increase in the scale of operation, i.e., an increase in sales with a corresponding increase in costs, $\mathrm{dTI}=\left[1-c^{\prime}(y)\right] \mathrm{d} y$. In contrast, corporate taxable income can increase with little increase in real sales or expenses if the response mainly comes through reporting margins (evasion/avoidance behavior).

Table 3 summarizes the changes in reported firm-level characteristics between 2012 and 2013 for firms located in different parts of the corporate taxable income distribution. The first group includes firms that relocated themselves from the old kink to the new kink in 2012-2013. This group thus represents firms that respond very actively to kink points.

In addition to these relocating firms, the table presents the statistics for three alternative firm groups. Without claiming any direct causality, these are chosen to provide comparison groups for the relocating firms, enabling us to take into account other potential changes in the economic environment of SME's that have taken place at the same time as the reform. The first group includes firms that do not belong to the SBC regime and have taxable corporate income between R300,000 and 400,000 in 2013. The second group comprises SBC firms with corporate taxable income between $\mathrm{R} 150,000$ and 250,000 in 2012 that are presumably unaffected by the reform. The third group comprises SBC firms that bunched at the upper kink in 2013 but not in 2012. In addition to changes in key firm-level variables, the table presents the average levels of the variables (in logs) in 2012 for the different groups.

The table underlines clear differences in the behavior of relocating firms and other similar-sized firms. It appears that relocating firms mainly respond through the reporting margin. For these firms, we observe an increase in their reported sales, but no corresponding increase in costs can be detected.

In more detail, relocating firms have a much larger average increase in sales compared to similar-sized non-SBC firms (14.5\% vs. 6.2\%). Unfortunately, our data do not include comprehensive and reliable information on expenses for non-SBC firms for 2013, which hampers a more detailed comparison between these groups. ${ }^{16}$ When compared to the group of firms with CTI below the upper kink in 2012 (R150k-250k), we find that relocating firms have a larger annual average increase in sales $(14.5 \%$ vs. $10.1 \%$ ), but also a notably smaller average increase in both expenses (5.2\% vs. $16.6 \%$ ) and cost of sales ( $8.9 \%$ vs. $10.1 \%)$. When comparing relocating firms to other bunching firms in 2013, we observe that these firms have an average annual sales increase of a similar magnitude (13.8\%) as the relocating firms. However, these firms also report significantly larger average increases in both expenses (17.9\%) and cost of sales (13.4\%) than the firms that also bunched in 2012, again highlighting that relocating firms appear to respond predominately by an increase in reported sales that is not accompanied by an increase in costs, which would clearly correspond to real responses.

In order to put these numbers into a more general context, recall that the change in tax incentives (the CIT rate dropped from $28 \%$ to $7 \%$ ) implies a $29 \%$ increase in the after-tax rate. Given the observed sales increase of $14.5 \%$ and an increase in expenses

\footnotetext{
16 However, when studying the years before 2013, we find that expenses increase more than sales for non-SBC firms in 2012-2011 and 2011-2010, similarly as for other comparison groups in the table for 2013-2012.
} 
Table 3 Descriptive statistics for firms in different parts of the corporate income distribution

\begin{tabular}{|c|c|c|c|c|c|c|}
\hline \multicolumn{7}{|c|}{ Bunchers in 2013 and 2012} \\
\hline$\triangle 2013-2012$ & $\triangle$ Sales & $\triangle$ Cost of sales & $\triangle$ Expenses & $\triangle \mathrm{CTI}$ & $\triangle$ Equity & $\triangle$ Cash \\
\hline Mean & .145 & .089 & .052 & .154 & .472 & .351 \\
\hline SE & .024 & .068 & .050 & .001 & .147 & .149 \\
\hline $\mathrm{N}$ & 185 & 118 & 193 & 194 & 157 & 160 \\
\hline Levels in 2012 & Sales & Cost of sales & Expenses & CTI & Equity & Cash \\
\hline Mean & 14.667 & 13.990 & 14.619 & 12.609 & 12.567 & 11.114 \\
\hline SE & .068 & .133 & .064 & .001 & .163 & .175 \\
\hline $\mathrm{N}$ & 186 & 123 & 194 & 194 & 191 & 170 \\
\hline
\end{tabular}

Non-SBC firms: CTI > $300 \&$ CTI $<400$ in 2013

\begin{tabular}{|c|c|c|c|c|c|c|}
\hline$\triangle 2013-2012$ & $\triangle$ Sales & $\triangle$ Cost of sales & $\triangle$ Expenses & $\triangle \mathrm{CTI}$ & $\triangle$ Equity & $\triangle \mathrm{Cash}$ \\
\hline Mean & .062 & .013 & - & .074 & .243 & -.003 \\
\hline SE & .010 & .033 & - & .005 & .032 & .042 \\
\hline $\mathrm{N}$ & 1090 & 465 & - & 1867 & 1093 & 1513 \\
\hline Levels in 2012 & Sales & Cost of sales & Expenses & CTI & Equity & Cash \\
\hline Mean & 14.305 & 14.245 & - & 12.674 & 13.798 & 11.516 \\
\hline SE & .036 & .075 & - & .005 & .035 & .054 \\
\hline $\mathrm{N}$ & 1122 & 473 & - & 1807 & 1699 & 1530 \\
\hline \multicolumn{7}{|c|}{ CTI $>150 \& \mathrm{CTI}<250$ in 2012} \\
\hline$\triangle 2013-2012$ & $\triangle$ Sales & $\triangle$ Cost of sales & $\triangle$ Expenses & $\triangle \mathrm{CTI}$ & $\triangle$ Equity & $\triangle \mathrm{Cash}$ \\
\hline Mean & .090 & .101 & .166 & .015 & .338 & .063 \\
\hline SE & .009 & .018 & .011 & .006 & .0287 & .038 \\
\hline $\mathrm{N}$ & 1841 & 1404 & 1916 & 1920 & 1518 & 1601 \\
\hline Levels in 2012 & Sales & Cost of sales & Expenses & CTI & Equity & Cash \\
\hline Mean & 14.575 & 13.839 & 14.425 & 12.169 & 12.851 & 11.267 \\
\hline SE & .021 & .039 & .020 & .007 & .036 & 0.045 \\
\hline $\mathrm{N}$ & 1855 & 1456 & 1919 & 1920 & 1819 & 1695 \\
\hline
\end{tabular}

Bunchers in 2013, not bunching in 2012

\begin{tabular}{lllllll}
\hline$\triangle 2013-2012$ & $\Delta$ Sales & $\Delta$ Cost of sales & $\triangle$ Expenses & $\Delta$ CTI & $\triangle$ Equity & $\Delta$ Cash \\
\hline Mean & .138 & .134 & .179 & .121 & .349 & .086 \\
SE & .024 & .036 & .031 & .012 & .067 & .090 \\
$\mathrm{~N}$ & 335 & 260 & 358 & 358 & 324 & 310 \\
\hline
\end{tabular}


Table 3 continued

\begin{tabular}{lllllll}
\hline \multicolumn{2}{l}{ Bunchers in 2013 and 2012} & & & & \\
\hline Levels in 2012 & Sales & Cost of sales & Expenses & CTI & Equity & Cash \\
\hline Mean & 14.906 & 14.163 & 14.782 & 12.643 & 13.249 & 11.467 \\
SE & .048 & .089 & .044 & .012 & .072 & .111 \\
$\mathrm{~N}$ & 343 & 267 & 358 & 358 & 355 & 329 \\
\hline
\end{tabular}

Table presents the descriptive statistics for firms located in different parts of the corporate taxable income (CTI) distribution in 2012 and 2013. For all groups, the variables are presented in logs, and the data are restricted such that outliers with $\triangle \log (\mathrm{CTI})>50 \%$ are dropped from the sample. This limitation is selected in order to better compare relocating firms that follow the upper kink point to other similar types of firms in the distribution. In addition to the firms that bunch at the upper kink both in 2012 and 2013, the table includes three suggestive comparison groups: non-SBC firms with corporate taxable income of R300,000400,000 in 2013, SBC firms with corporate taxable income of R150,000-250,000 in 2012 and SBC firms that bunched at the upper kink in 2013 but not in 2012. Cash includes cash equivalents that are easily convertible into a known cash amount. Data on expenses for non-SBC firms are not available for 2013

of $5.2 \%$, the implied sales elasticity was 0.5 and the costs elasticity only 0.18 for the relocating firms. Therefore, in relative terms, the relocating firms appear to react by reporting more sales relative to costs because of the tax reduction. One possible explanation for this finding is that firms could have hidden part of their sales in 2012 and start to report a larger fraction in 2013 when the tax rate was reduced. Additionally, for the firms in the neighborhood of the upper kink before 2013, we approximate the average marginal increase in costs per an additional Rand of sales to be $0.64 .{ }^{17}$ By simply assuming that this broader measure would roughly approximate underlying real economic activity, we would therefore expect the reported costs of the relocating firms to increase by 0.64 times the sales increase, i.e., by approximately $9 \%$ if real responses drive the response. The observed cost increase (5.2\%) was, however, much smaller.

To support this finding, one further distinctive difference between relocating firms and other groups in Table 3 is the development of cash in the firms' balance sheets. ${ }^{18}$ There is a clear increase in reported average cash holdings (35\%) for the relocating firms between 2012-2013. In contrast, cash holdings increase much less in the other groups $(0-8.5 \%)$. One underlying driver for the appearance of the additional cash could be the increase in reported sales when the marginal CIT rate was reduced for firms that bunched at the upper kink point in 2012.

To summarize, several empirical observations support the proposition that reporting responses are likely to have a large role in explaining the observed firm behavior. First, the bunching at the upper kink point is very pronounced right at the threshold, which is not compatible with real economic adjustments along many different margins that are subject to considerable uncertainty, such as demand-side effects and actual total costs. Second, a large share of bunching firms respond sharply and immediately to the

\footnotetext{
17 Average $c^{\prime}(y)$ in the neighborhood of the upper kink $(+/-\mathrm{R} 75,000)$ is approximated by utilizing an OLS estimation where we regress sales on expenses (including reported wages) in order to recover what is the marginal increase in costs when sales are increased by 1 Rand.

18 Cash includes cash equivalents that are easily convertible into a known cash amount.
} 
relocation of the kink point, which further supports the earlier conclusion. In particular, the excess mass at the old kink point disappears instantly when the upper kink point is relocated. Third, the observed small change in the scale of activities of the firms that responded distinctly to the increase in the upper kink point is not consistent with a relatively large observed increase in reported sales, which adds our final piece of descriptive evidence suggesting significant reporting behavior.

However, it is possible that the overall response is a sum of real and reporting activities. For example, some of the relocating firms could have first responded by adjusting their real scale of operation and then utilized tax-planning techniques or some degree of misreporting to exactly match the new threshold value. Therefore, we are obviously not able to provide a detailed numerical decomposition of real and reporting responses. In addition, as our evidence on the mechanisms is mostly descriptive, the findings need to be interpreted as suggestive. Nevertheless, given these limitations, our results tend to indicate that reporting behavior can explain a significant part of the response. This makes it less likely that the original goal of increasing real economic activity by applying a graduated corporate tax rate schedule for small businesses can be reached.

\subsubsection{The lower kink point}

Figure 12 in Appendix shows the corporate income distributions in different years around the lower kink point. Similarly as with the upper kink point, the peak of the corporate income distribution follows the changes in the lower kink point. However, as the annual changes in the location of the lower kink are small, this variation does not allow us to precisely characterize the mechanisms behind the observed behavior. This is because the observed excess mass in the distribution overlaps with the bunching regions of both future and past kink points, which at least partly prevents us from disentangling different types of responses. Furthermore, the figure illustrates that if there are some types of frictions related to adjusting to these small changes in the location of the kink point for some small firms, we would observe a scattered, humpshaped distribution below the kink, as can be seen in the upper graph of Fig. 3, which pools all the years 2010-2013 together. Similarly as with the upper kink point, Fig. 13 in Appendix shows that a notable share of firms (30\%) follow the movements of the lower kink point, but these estimates could be at least partly affected by the fact that the changes in the location of the lower tax threshold have been small.

\subsection{Characterizing reporting behavior}

The results above suggest that firms respond to the CIT kinks to a notable extent by means of reporting measures. Next, we further characterize these channels by utilizing the development of firm-level factors, such as sales, expenses and balance sheet information, around the CIT kinks, as in Almunia and Lopez-Rodriguez (2018). ${ }^{19}$ This examination can shed more light on how firms locate themselves at the kink

\footnotetext{
19 Utilizing a similar approach, Almunia and Lopez-Rodriguez (2018) study the factors that drive large firms in Spain to respond to a revenue threshold above which they face stricter tax enforcement.
} 

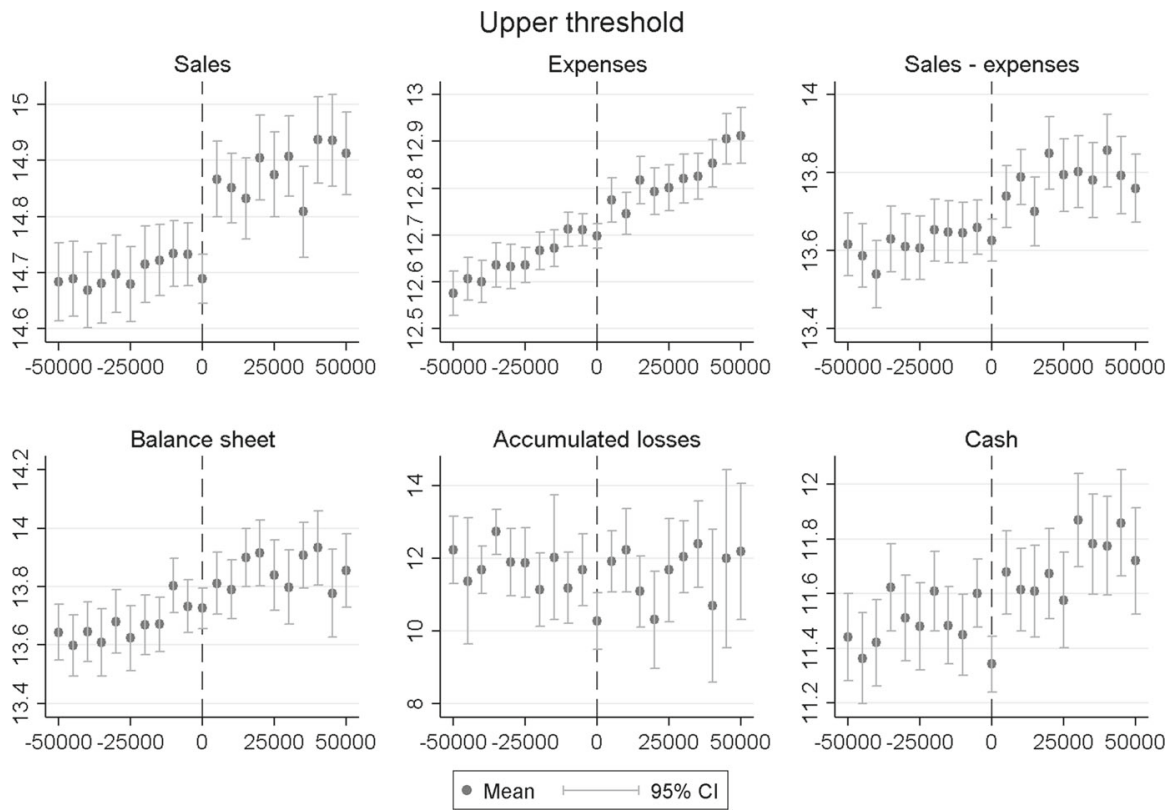

Fig. 6 Averages of firm-level factors in different corporate taxable income bins around the upper CIT threshold, 2010-2012. Notes Figure shows the log averages with 95\% confidence intervals for various firmlevel factors around the upper kink point in bins of R5,000 in 2010-2012. Expenses include cost of sales, other expenses and wages. Balance sheet denotes the total balance sheet value of the firm. Cash includes cash equivalents that are easily convertible into a known cash amount

point, and whether the firms that bunch at the kink differ from other firms located close to the kink. Nevertheless, this analysis does not offer causal evidence of behavioral patterns, but rather provides descriptive evidence of the potential mechanisms of reporting behavior.

Figure 6 shows the averages of sales, expenses (including cost of sales, other expenses and wages), sales minus expenses, and total balance sheet value, accumulated losses and cash holdings (including cash equivalents) in different bins of corporate taxable income around the upper CIT kink point. The figure includes the years 20102012, for which the more detailed balance sheet information was available in our data.

We observe that sales and sales minus expenses are smaller in the bins below the kink and jump in a discontinuous manner above it. In the absence of the kink point and reporting responses, we would expect the firm-level variables to evolve smoothly as taxable corporate income increases. Thus, this type of discontinuous development at the threshold gives indicative evidence that the kink point affects the behavior of firms, especially related to items that affect the level of corporate taxable income. This evidence thus suggests that underreporting of sales can at least partly explain the observed bunching behavior, rather than overreporting of expenses, as expenses develop in a fairly continuous manner in the bins in the neighborhood of the 
kink. However, as this evidence is only descriptive, we cannot consistently rule out misreporting of expenses.

Furthermore, the figure appears to reject the potential mechanism that bunching is driven by real economic responses of more profitable firms. This could in theory explain the large income responses of the relocating firms discussed above. In contrast, the evidence suggests that profitability, characterized by sales-expenses, is lower for firms just at the kink. However, we interpret this finding as stemming from underreporting of income rather than providing evidence of the bunching firms being less productive (in real terms) compared to other firms with similar corporate income levels.

We find no significant differences in the total balance sheet value of the firms in the neighborhood of the kink, suggesting that there are no significant differences in the overall size of the firms around the kink. This also tentatively indicates that the overall extent of sales underreporting for the bunching firms is likely not substantial. However, when looking at specific items of the balance sheet that can be utilized to adjust annual reported income, we do find some differences between bunching firms and other firms close to the kink. The figure shows that bunching firms have smaller accumulated losses, suggesting that firms aim to locate themselves right at the kink point by utilizing these types of legal tax-planning measures. By utilizing accumulated losses, firms can aim to adjust their reported taxable income over time such that they

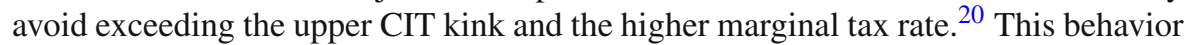
thus represents pure intertemporal legal tax avoidance behavior. Also, following the evidence in Table 3, we find that bunching firms have significantly less cash and cash equivalents in their balance sheet compared to other firms close to the threshold. This finding is consistent with underreported sales, as it implies less reported cash income for the firm, which translates into smaller cash holdings in the balance sheet.

Overall, the above findings suggest that both underreporting and avoidance measures explain the observed bunching responses at the upper kink point. This is consistent with the sharp changes in bunching behavior when the kink point was relocated. Nevertheless, it is likely that several types of reporting responses are occurring simultaneously, which makes it difficult to make more rigorous calculations or conclusions about the significance of various types of responses.

Figure 14 in Appendix shows the development of firm-level factors around the lower kink point. In contrast to the findings at the upper kink, we find no significant differences in sales or expenses for the bunching firms, except perhaps that sales appear to be slightly larger and expenses slightly smaller just below the kink. As discussed in Sect. 5.1, this could stem from firms below the kink antedating their sales, as an increase in sales below the lower kink does not affect tax liability, in contrast to the upper kink point, where the tax rate is positive on both sides of the threshold. Differences in incentives at the threshold also imply that the observations for the upper kink are not necessarily applicable to the lower kink, and vice versa. Furthermore, we find that total balance sheet values appear to be larger in a region below the kink where the bunching behavior also occurs, which suggests that firms are larger below the lower

\footnotetext{
20 A tax loss incurred in any business activity in earlier tax years may be carried forward indefinitely and set off against future positive corporate income, provided that the company remains active during the whole assessment period.
} 
kink than just above it. However, we find that cash holdings are smaller for firms just at the kink, suggesting that underreporting of income could also explain at least some of the observed bunching behavior also at the lower kink point.

Finally, one potential channel of response is income-shifting between tax bases. Firm owners might prefer withdrawing (usually) more leniently taxed corporate income from the firm up to the upper CIT threshold instead of wages. ${ }^{21}$ Unfortunately, we do not have data on the salary payments from the firm to the owner to study this channel of response directly. However, our data include total annual wage payments by the firms. We use this as a proxy for potential income-shifting between the corporate and individual tax bases. In Appendix in Fig. 15, we plot the average total wage payments by corporate income bins for both CIT thresholds and observe that the wage payments are higher above the kink point, especially around the upper kink point. These findings are compatible with the presence of income-shifting from the corporate tax base to the labor income tax base. However, one needs to be careful in the interpretation of this, as the wage variable captures the total wage payments by the firms and the wage payments to the owner of the firm might be only a small share of the total wages.

\section{Conclusions}

In this paper, we study the responsiveness of small- and medium-sized firms to corporate income tax rates using high-quality and population-wide administrative data from South Africa. Our results based on examining bunching behavior around CIT kink points show that firms clearly respond to these tax incentives. Our descriptive evidence suggests that a notable share of this response is induced by reporting effects rather than real economic changes in business activity. In particular, sharp excess bunching and immediate and large firm-level taxable income responses to changes in the location of the kink point suggest a significant reporting response. Those firms that locate exactly at an earlier kink point and at a new kink point at a higher income level report increased sales, but the sales increase is not fully compatible with changes in real economic activity, suggesting that reporting behavior is a significant driver of the response.

A detailed examination of firm-level factors for firms just below and above the kink point reveals that firms below the kink point report lower sales and lower profitability. While this finding cannot be given a causal interpretation, it is compatible with the notion that firms are underreporting their sales in order to avoid paying higher taxes. Such firms also report lower cash holdings, another feature consistent with underreported sales. In addition, we find that firms locating at the kink point report

\footnotetext{
21 For example, the personal income tax rates on wage income for the tax year 2012-2013 were as follows: $18 \%$ for incomes not exceeding R 160,$000 ; 25 \%$ of the amount above R 160,000 up to R 250,$000 ; 30 \%$ of the amount exceeding R250,000 up to R346,000; 35\% of the amount above R346,000 up to R484,000; $38 \%$ of the amount above R484,000; and 40\% of the amount above R617,000. However, there is a tax rebate of $\mathrm{R} 11,400$, which means that wage income is effectively tax free until R63,000. This rather complicated tax schedule for wage income creates income-shifting incentives. Around the upper tax kink, this creates a tax incentive to withdraw wage income until R250,000 instead of corporate income as the marginal tax rate on corporate income is higher above the upper kink than on wage income.
} 
lower accumulated losses, which is consistent with (legal) tax-planning measures to avoid the higher marginal CIT rate. All this suggestive evidence points to significant reporting responses, but given the tax rate variation and the available data, an exact decomposition of legal avoidance vs. evasion is not feasible.

In a broader context, our findings are somewhat counter to the rationale of using a turnover tax regime in developing economies to limit tax evasion opportunities (see, e.g., Best et al. 2015). In a mandatory turnover tax system, evasion can be partly mitigated if underreporting of sales is more difficult than overreporting of costs. For example, Bachas and Soto (2015) find the revenue elasticity to be smaller than the cost elasticity in the Costa Rican context. In contrast, Carrillo et al. (2017) find that firms respond to a tax evasion intervention more by changes in reported revenue than reported costs. Based on the (admittedly indirect) findings in this paper, we also argue that the superiority of turnover tax in deterring evasion may be linked with the institutional details related to its implementation. Underreporting of sales can be relatively easy, for example, for small traders whose transactions take place predominantly using cash. Nevertheless, turnover tax can, of course, entail lower compliance costs. This would favor applying it irrespective of its consequences for revenue efficiency.

Finally, based on our findings, it is not obvious that a graduated corporate tax rate schedule is effective in reaching its goals. Similar to the findings of Devereux et al. (2014) for the UK, part of the impact of tax changes appears to be driven by reporting behavior, thus mitigating the original goal of encouraging greater economic activity and job creation by small- and medium-sized firms by applying a graduated tax rate schedule. Therefore, the welfare losses stemming from firm responses are presumably smaller in the present context, where reporting responses are likely to be a significant factor, compared to a case where all of the response arises from changes in pure real economic behavior, even though the effects of reporting and real responses on government tax revenue are in principle similar (at least in the short run). An important caveat to these conclusions is that lower effective average tax rates for small businesses may encourage the formalization of companies. This is an important topic for further analysis, perhaps not necessarily in the South African context, where the extent of formalization is large, but probably in many other developing or emerging economies.

Acknowledgements We are grateful to two anonymous referees and Essi Eerola, Elizabeth Gavin, Francois Gerard, Tomi Kyyrä, Andreas Peichl, Mazhar Waseem, and seminar audiences at the National Treasury, Helsinki Center for Economic Research, ZEW Public Finance conference in Mannheim, the IIPF conference in Lake Tahoe, Uppsala University, VATT, the UNUWIDER/National Treasury Conference in Pretoria, the Zurich Center for Economic Development and the IFS TAXDEV workshop in London for their useful comments. Harju gratefully acknowledges funding from the Foundation for Economic Education.

The opinions expressed in this article are those of the authors and do not necessarily reflect the views of the UNU-WIDER, its Board of Directors, or the countries they represent.

Open Access This article is licensed under the terms of the Creative Commons AttributionNonCommercial-ShareAlike 3.0 IGO License, which permits any non-commercial use, sharing, adaptation, distribution and reproduction in any medium or format, as long as you give appropriate credit to the UNUWIDER, provide a link to the Creative Commons licence, and indicate if changes were made. If you remix, transform, or build upon this article or a part thereof, you must distribute your contributions under the same licence as the original.

The use of the UNU-WIDER's name, and the use of the UNU-WIDER's logo, shall be subject to a separate written licence agreement between the UNU-WIDER and the user and is not authorized as part 
of this CC-IGO licence. Note that the link provided above includes additional terms and conditions of the licence.

The images or other third party material in this article are included in the article's Creative Commons licence, unless indicated otherwise in a credit line to the material. If material is not included in the article's Creative Commons licence and your intended use is not permitted by statutory regulation or exceeds the permitted use, you will need to obtain permission directly from the copyright holder.

To view a copy of this licence, visit http://creativecommons.org/licenses/by-nc-sa/3.0/igo/.

\section{Appendix}

Table 4 Excess bunching at the lower and upper CIT kinks with different assumptions about the excluded range and the order of the polynomial

\begin{tabular}{|c|c|c|c|c|c|c|}
\hline \multirow[t]{2}{*}{ Lower kink } & \multicolumn{6}{|c|}{ Order of polynomial (baseline $=7$ ) } \\
\hline & 1 & 2 & 4 & 6 & 8 & 10 \\
\hline Excess bunching & 5.356 & 8.695 & 5.427 & 4.421 & 4.267 & 3.439 \\
\hline \multirow[t]{3}{*}{ Std. error } & .385 & 676 & .664 & .553 & .676 & .774 \\
\hline & \multicolumn{6}{|c|}{$\underline{\text { Bunching region }(\text { baseline }=|10| \text { ) }}$} \\
\hline & $|5|$ & $|7|$ & $|13|$ & $|15|$ & $|20|$ & $|25|$ \\
\hline Excess bunching & 3.677 & 4.220 & 5.362 & 5.794 & 4.460 & 6.599 \\
\hline Std. error & .251 & .308 & .841 & 1.197 & 3.305 & 12.244 \\
\hline \multirow[t]{2}{*}{ Upper kink } & \multicolumn{6}{|c|}{ Order of polynomial (baseline $=7$ ) } \\
\hline & 1 & 2 & 4 & 6 & 8 & 10 \\
\hline Excess bunching & 16.179 & 13.864 & 12.687 & 11.032 & 9.565 & 8.845 \\
\hline \multirow[t]{3}{*}{ Std. error } & .408 & .496 & .660 & .862 & .842 & 1.004 \\
\hline & \multicolumn{6}{|c|}{ Bunching region $($ baseline $=|10|$ ) } \\
\hline & $|3|$ & $|5|$ & $|7|$ & & $|13|$ & $|15|$ \\
\hline Excess bunching & 6.795 & 8.031 & 8.443 & & 11.825 & 12.979 \\
\hline Std. error & .271 & .380 & .480 & & 1.073 & 1.488 \\
\hline
\end{tabular}

Table shows the excess bunching estimates and standard errors with different assumptions about the order of the polynomial and the bunching region. The baseline estimate is $4.519(0.452)$ at the lower kink and $11.025(0.755)$ at the upper kink. Increasing the degree of the polynomial in estimating the counterfactual distribution decreases the excess mass. Increasing the bunching region on both sides of the kink from 5 to 15 increases the excess bunching estimate, but the differences are not in general significant for values between 7 and 15 

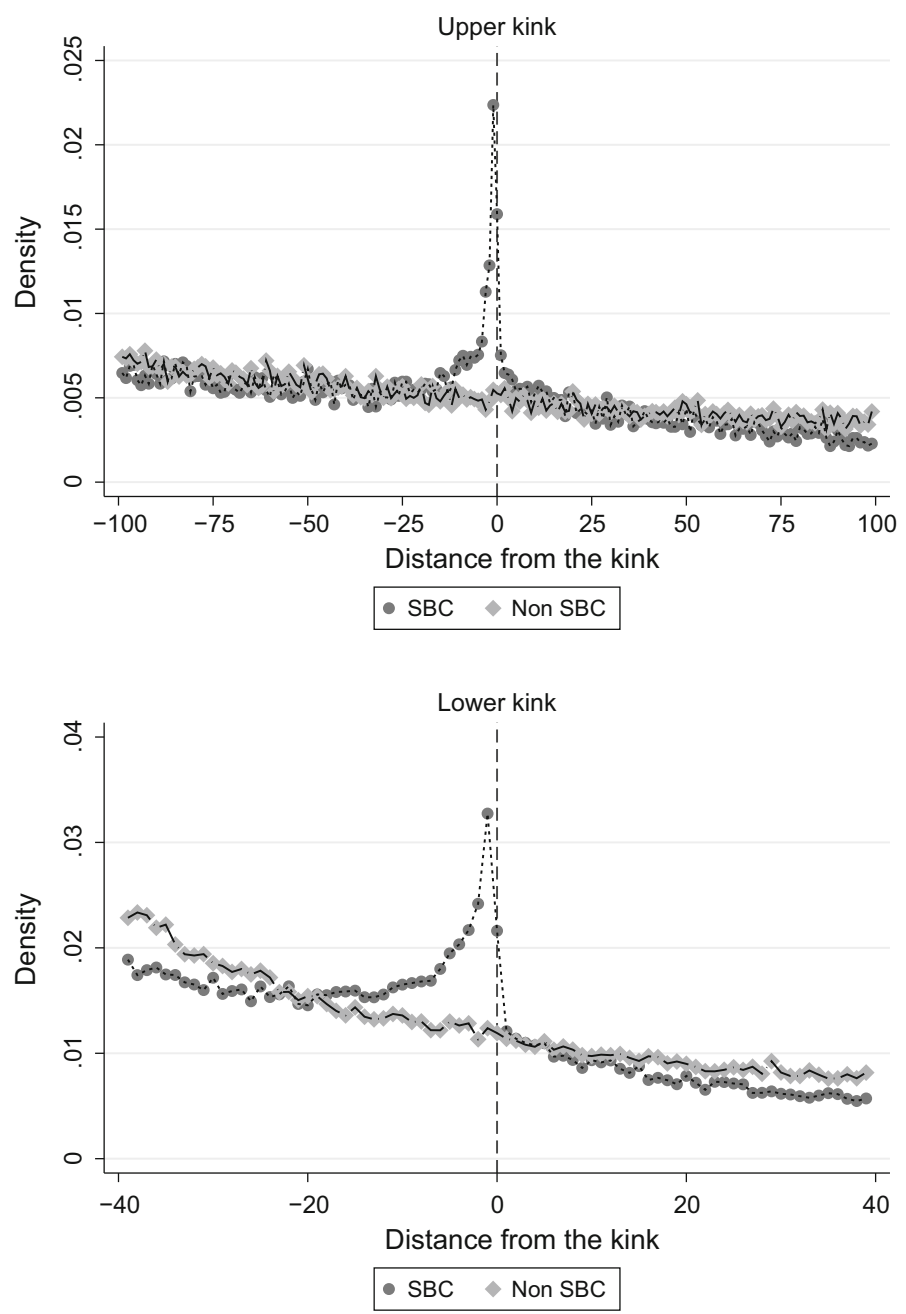

Fig. 7 Corporate taxable income distributions of SBC and non-SBC firms around the CIT kink points, 2010-2013. Notes Figure shows the corporate taxable income density distributions of firms around the upper and lower kink points among SBC and non-SBC firms in bins of R1,000 in 2010-2013. The kink points only apply to SBC firms. Non-SBC firms face a flat tax rate of $28 \%$ throughout the corporate taxable income distribution 

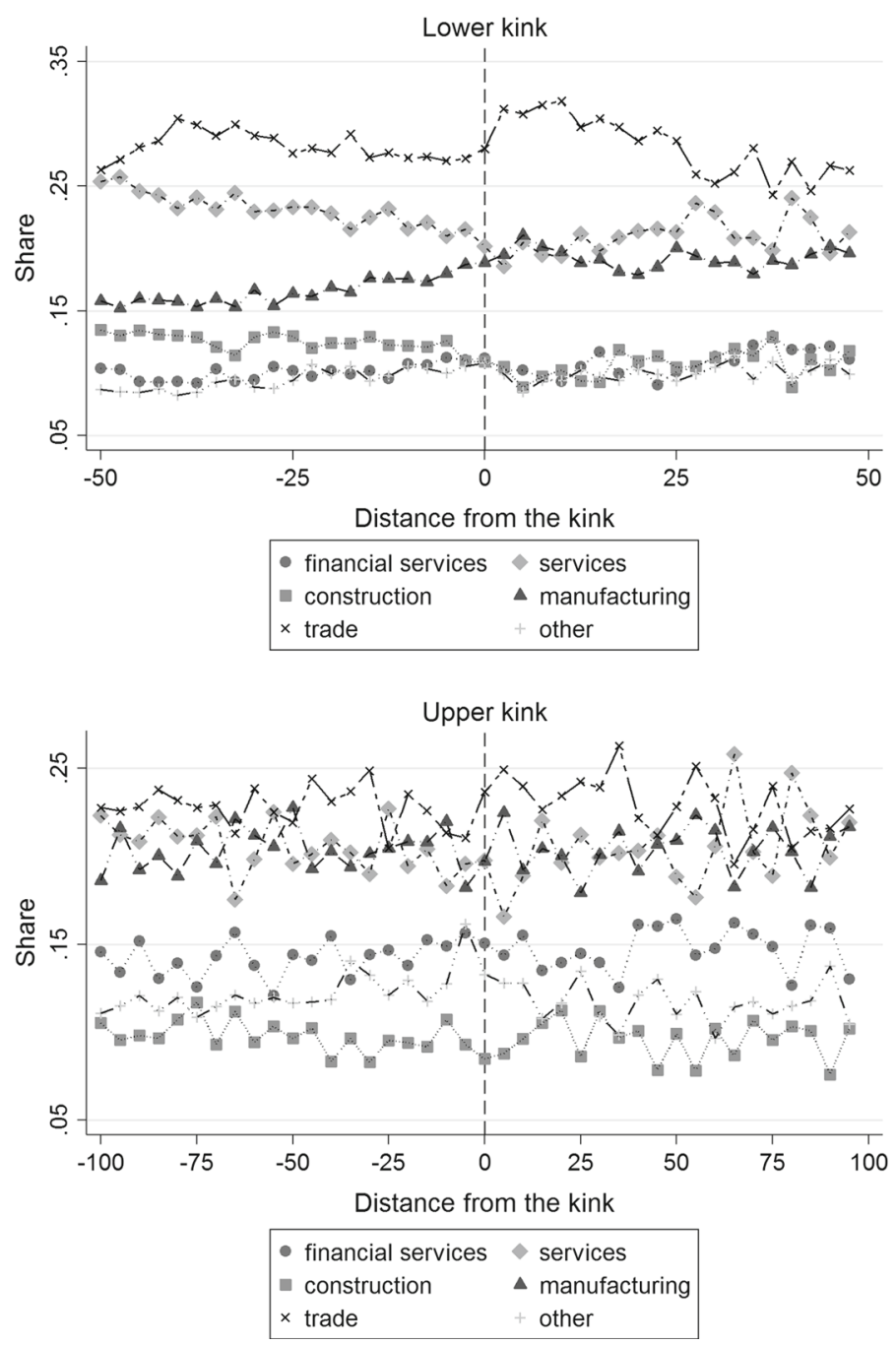

Fig. 8 Share of firms in different industry categories around the CIT kink points, 2010-2013. Notes Figure shows the average shares of firms in different industry categories in bins of R2,500 around the lower kink and in bins of R5,000 around the upper kink in 2010-2013 

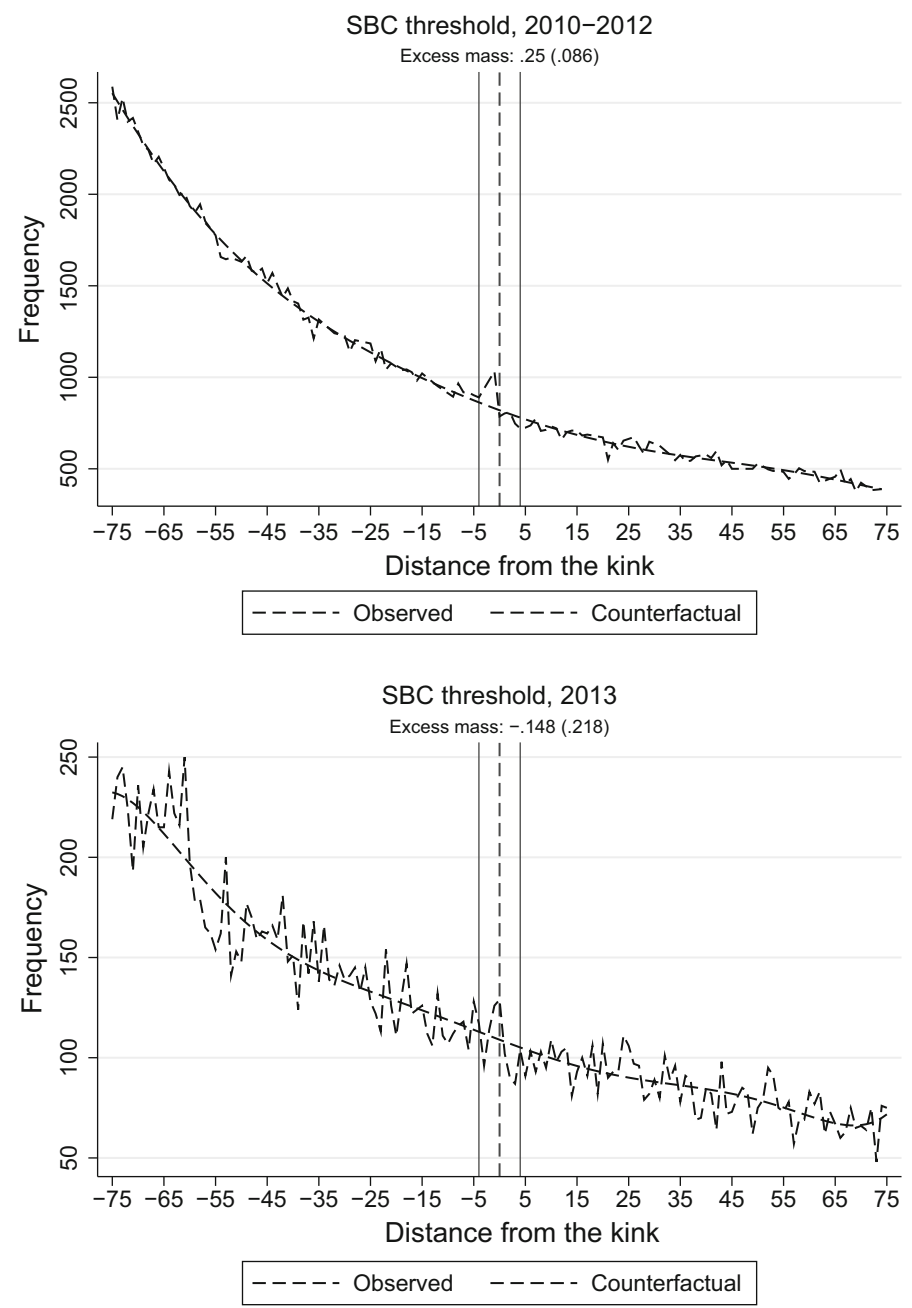

Fig. 9 Gross corporate income distributions around the SBC eligibility threshold: 2010-2012 and 2013. Notes Figure shows the gross income distributions and estimated counterfactual distributions relative to the SBC eligibility threshold in bins of R1,000, and the excess mass estimates and bootstrapped standard errors in 2010-2012 and 2013. The eligibility threshold was R14 million in 2010-2012 and R20 million in 2013. The dashed line at zero denotes the threshold, and the solid lines around the threshold denote the excluded region when estimating the counterfactual 


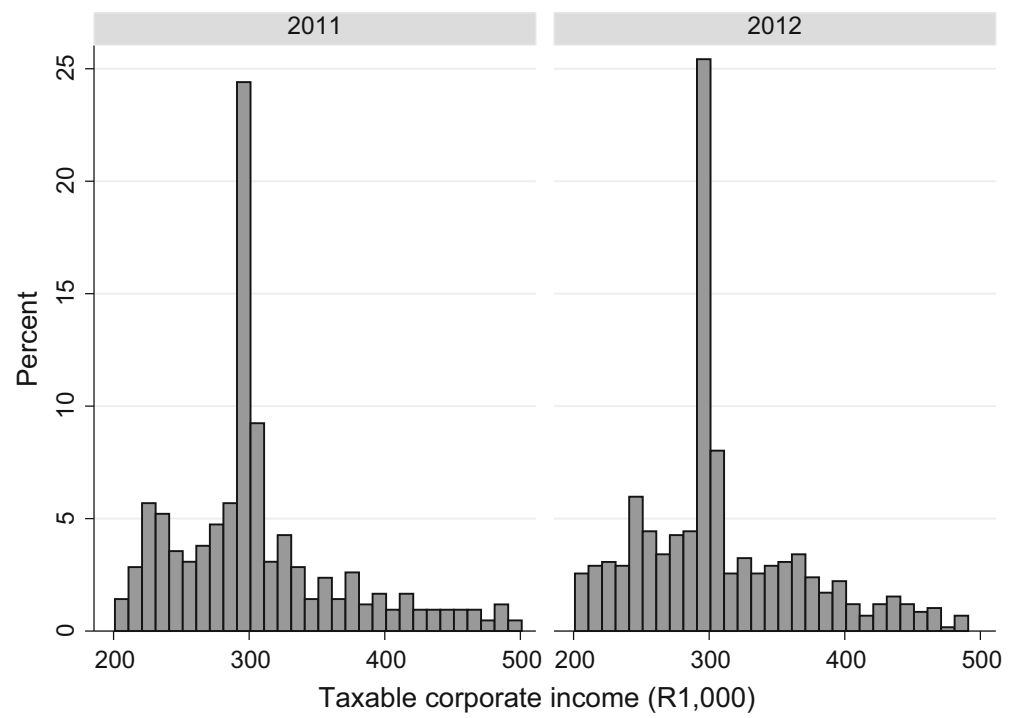

Fig. 10 Taxable income distributions for the firms that bunched in 2013: years 2011 (left) and 2012 (right). Notes Figure shows the taxable income distributions in bins of R10,000 for the firms that were located at the R350,000 kink point in 2013 (within the bunching window of +/- R10,000) for the years 2011 (left-hand side) and 2012 (right-hand side). Before 2013, the corporate tax rate kink point was R300,000

One year persistence rates
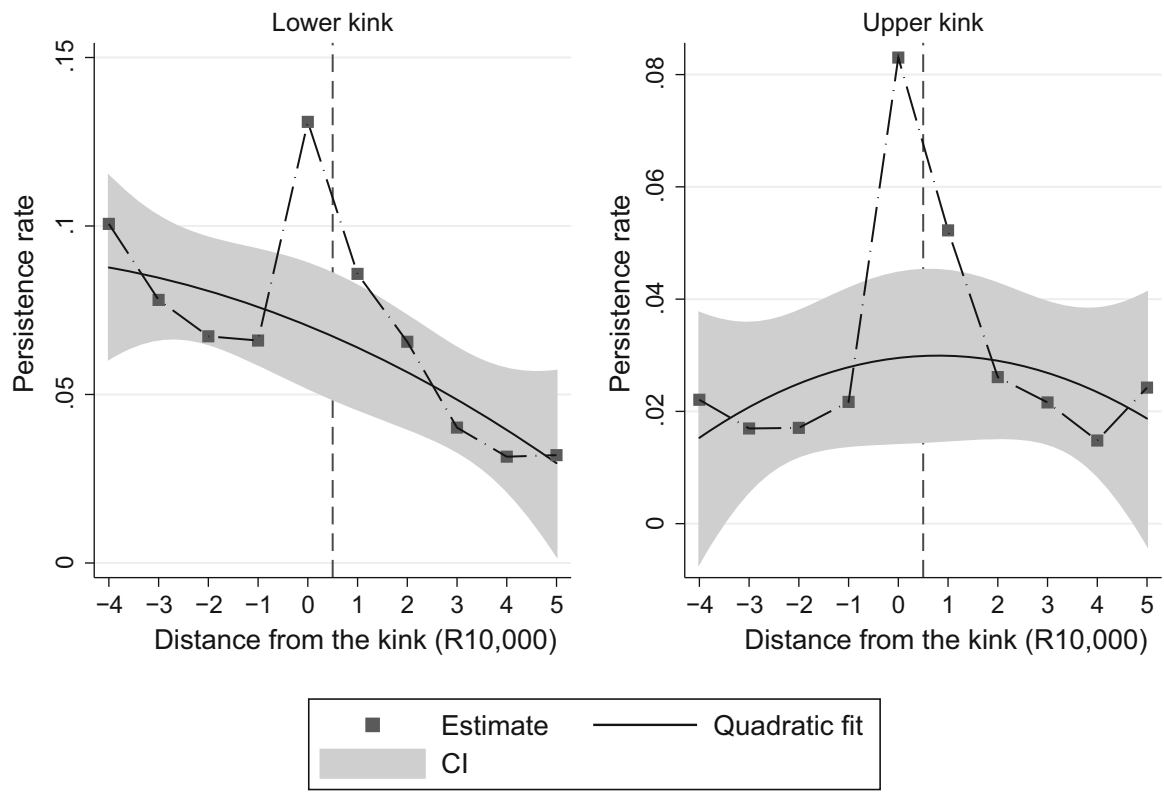

Fig. 11 One-year persistence rates around lower and upper CIT kink points. Notes Figure presents the persistence rates of firms within different bins of R10,000 around the lower and upper kink points in 20102013. The persistence rate denotes the probability that a firm remains in the same bin from one year to another 


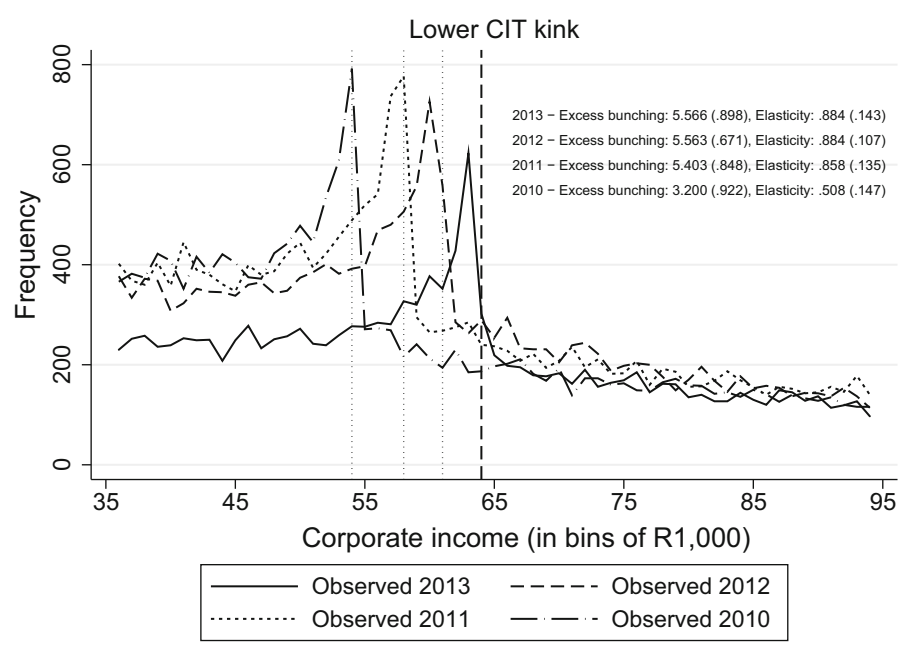

Fig. 12 Changes in the location of the lower CIT kink point. Notes Figure shows the observed distributions of taxable corporate income around the lower corporate tax rate kink in bins of R1,000, and the excess mass and local taxable corporate income elasticities at the kink points with bootstrapped standard errors in 2010-2013. The kink points in different years are marked with dashed vertical lines. The lower kink points were R54,200, R57,000, R59,740 and R63,556 in 2010, 2011, 2012 and 2013, respectively

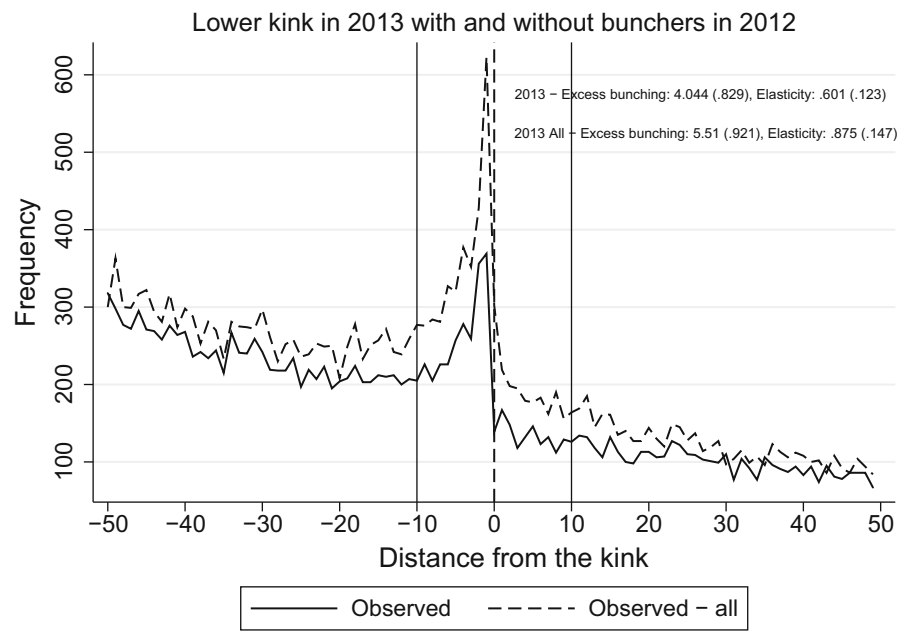

Fig. 13 Excess bunching at the lower CIT kink in 2013 with and without the firms that bunched at the kink in 2012. Notes Figure shows the observed distributions of taxable corporate income relative to the lower corporate tax rate kink in bins of R1,000, and the excess mass and local taxable corporate income elasticities at the kink point with bootstrapped standard errors using data for 2013. The figure includes the distributions and estimates for the entire sample and the sample excluding the firms that bunched at the lower kink in 2012. The lower kink was R59,740 in 2013 and R63,556 in 2012 


\section{Lower threshold}
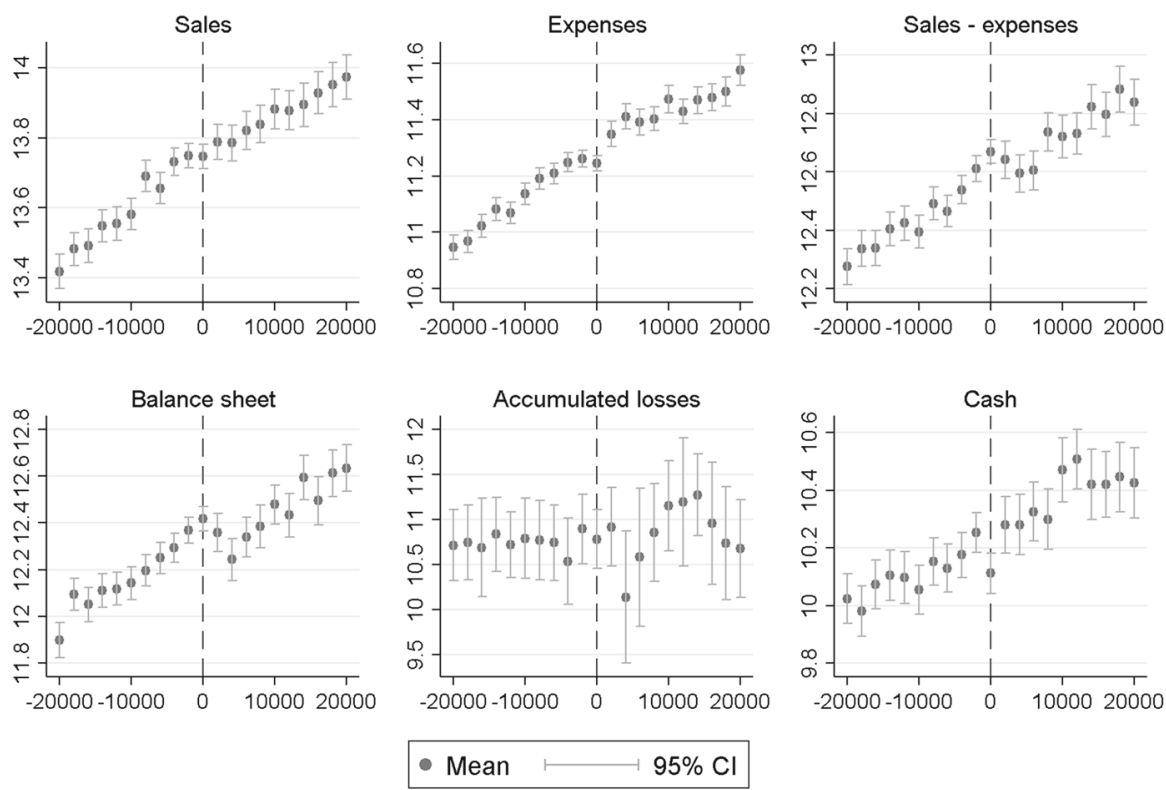

Fig. 14 Averages of firm-level factors in different taxable corporate income bins around the lower CIT threshold, 2010-2012. Notes Figure shows the log averages with 95\% confidence intervals for various firmlevel factors around the lower kink point in bins of R2,000 in 2010-2012. Expenses includes cost of sales, other expenses and wages. Balance sheet denotes the total balance sheet value of the firm. Cash includes cash equivalents that are easily convertible to a known cash amount
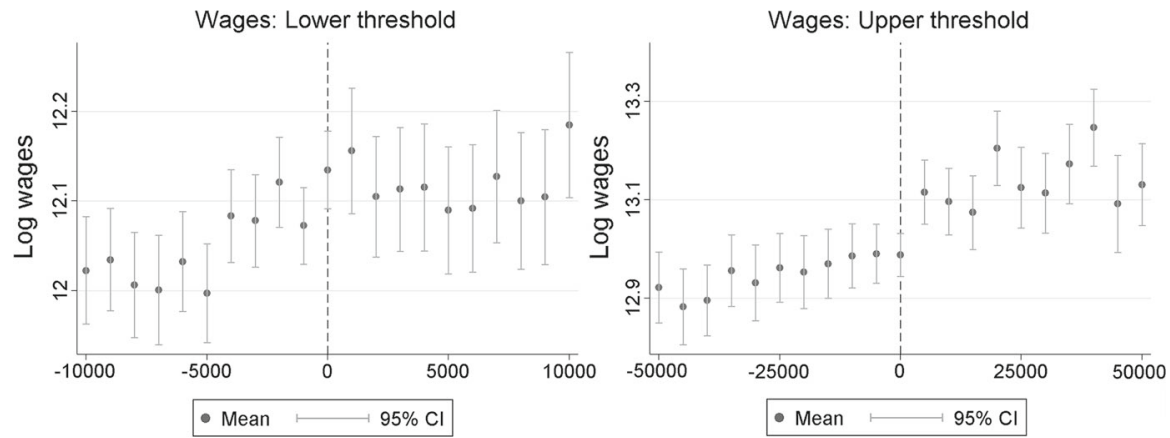

Fig. 15 Wage sums by corporate taxable income bins around the lower (left) and upper (right) CIT threshold, 2010-2012. Notes Figure shows the log averages with 95\% confidence intervals for wage sums around the lower kink point in bins of R1,000 (left) and upper kink point in bins of R5,000 (right) in 2010-2012

\section{References}

Almunia, M., \& Lopez-Rodriguez, D. (2018). Under the radar: The effects of monitoring firms on tax compliance. American Economic Journal: Economic Policy, 10(1), 1-38.

Bachas, P., \& Soto, M. (2015). Not(ch) your average tax system: Corporate taxation under weak enforcement. Mimeo: University of Berkeley. 
Bastani, S., \& Selin, H. (2014). Bunching and non-bunching at kink points of the Swedish tax schedule. Journal of Public Economics, 109, 36-49.

Besley, T., \& Persson, T. (2013). Chapter 2-Taxation and development. In M. F. Alan, J. Auerbach, R. Chetty, \& E. Saez (Eds.), Handbook of public economics, Volume 5 of Handbook of public economics (Vol. 5, pp. 51-110). Amsterdam: Elsevier.

Best, M., Brockmeyer, A., Kleven, H., Spinnewijn, J., \& Waseem, M. (2015). Production vs revenue efficiency with limited tax capacity: Theory and evidence from Pakistan. Journal of Political Economy, 123, 1311-1355.

Boonzaaier, W., Harju, J., Matikka, T., \& Pirttilä, J. (2016). How do small firms respond to tax schedule discontinuities? Evidence from South African tax registers. Working paper 2016:36, UNU-WIDER.

Carrillo, P., Pomeranz, D., \& Singhal, M. (2017). Dodging the taxman: Firm misreporting and limits to tax enforcement. American Economic Journal: Applied Economics, 9, 144-164.

Chetty, R. (2009). Is the taxable income elasticity sufficient to calculate deadweight loss? The implications of evasion and avoidance. American Economic Journal: Economic Policy, 1(2), 31-52.

Chetty, R., Friedman, J. N., Olsen, T., \& Pistaferri, L. (2011). Adjustment costs, firm responses, and micro vs. macro labor supply elasticities: Evidence from Danish tax records. The Quarterly Journal of Economics, 126(2), 749-804.

Devereux, M. P., Liu, L., \& Loretz, S. (2014). The elasticity of corporate taxable income: New evidence from UK tax records. American Economic Journal: Economic Policy, 6(2), 19-53.

Fisman, R., \& Svensson, J. (2007). Are corruption and taxation really harmful to growth? Firm level evidence. Journal of Development Economics, 83(1), 63-75.

ILO. (2014). Women and men in the informal economy: A statistical picture. Technical Report Second Edition. International Labor Office, Geneva.

Keen, M. (2012). Taxation and development: Again. IMF Working Papers 12/220, International Monetary Fund.

Kleven, H. (2016). Bunching. Annual Review of Economics, 8, 435-464.

Kleven, H. J., \& Waseem, M. (2013). Using notches to uncover optimization frictions and structural elasticities: Theory and evidence from Pakistan. Quarterly Journal of Economics, 128(2), 669-723.

Lediga, C., Riedel, N., \& Stohmaier, K. (2016). Corporate taxes and firm behavior-Evidence from South Africa. Unpublished manuscript, University of Bochum.

Leibbrandt, M., Finn, A., \& Oosthuizen, M. (2016). Poverty, inequality, and prices in post-apartheid South Africa. In C. Arndt, A. McKkay, \& F. Tarp (Eds.), Growth and poverty in Sub-Saharan Africa (pp. 393-420). Oxford: Oxford University Press.

Mascagni, G. (2017). From the lab to the field: A review of tax experiments. Journal of Economic Surveys, 32(2), 273-301.

Medina, L., Jonelis, A., \& Cangul, M. (2017). The informal economy in Sub-Saharan Africa: Size and determinants. Technical Report Working Paper 17/156, IMF.

Pomeranz, D. (2015). No taxation without information: Deterrence and self-enforcement in the value added tax. American Economic Review, 105(8), 2539-69.

Prichard, W., Cobham, A., \& Goodall, A. (2014). The ICTD government revenue dataset. Working Paper 19, International Centre for Taxation and Development.

Saez, E. (2010). Do taxpayers bunch at kink points? American Economic Journal: Economic Policy, 2(3), 180-212.

Saez, E., Slemrod, J., \& Giertz, S. H. (2012). The elasticity of taxable income with respect to marginal tax rates: A critical review. Journal of Economic Literature, 50(1), 3-50.

Statistics South Africa (2015). Labour market dynamics in South Africa, 2015. Technical report.

Publisher's Note Springer Nature remains neutral with regard to jurisdictional claims in published maps and institutional affiliations. 